\title{
Group velocity maps using subspace and transdimensional inversions: ambient noise tomography in the western part of Java, Indonesia
}

\author{
Shindy Rosalia ${ }^{\oplus, 1,2}$ Phil Cummins, ${ }^{2,3}$ Sri Widiyantoro ${ }^{\bullet}, 2,4$ Tedi Yudistira, ${ }^{2}$ Andri \\ Dian Nugraha ${ }^{2}$ and Rhys Hawkins ${ }^{3}$ \\ ${ }^{1}$ Graduate Program of Geophysical Engineering, Faculty of Mining and Petroleum Engineering, Institute of Technology Bandung, Jalan Ganesa No. 10, \\ Bandung 40132, Indonesia \\ ${ }^{2}$ Global Geophysics Research Group, Faculty of Mining and Petroleum Engineering, Institute of Technology Bandung, Jalan Ganesa No. 10, Bandung 40132, \\ Indonesia.E-mail: ilikwidi@gmail.com \\ ${ }^{3}$ Research School of Earth Sciences, Australian National University, Canberra, ACT 2601, Australia \\ ${ }^{4}$ Center for Earthquake Science and Technology, Institute of Technology Bandung, Jalan Ganesa No. 10, Bandung 40132, Indonesia.
}

\begin{abstract}
SUMMAR Y
In this paper, we compare two different methods for group velocity inversion: iterative, least-squares subspace optimization and probabilistic sampling based on the transdimensional (Trans-D) Bayesian method with tree-based wavelet parametrization. The wavelet parametrization used a hierarchical prior for wavelet coefficients which could adapt to the data. We applied these inversion methods for ambient noise tomography of the western part of Java, Indonesia. This area is an area prone to multiple geological hazards due to its proximity to the subduction of the Australia Plate beneath Eurasia. It is therefore important to have a better understanding of upper crustal structure to support seismic hazard and disaster mitigation efforts in this area. We utilized a new waveform data set collected from 85 temporary seismometers deployed during 2016-2018. Cross-correlation of the waveform data was applied to retrieve empirical Rayleigh wave Green's functions between station pairs, and the spatial distribution of group velocity was obtained by inverting dispersion curves. Our results show that, although computationally expensive, the Trans-D Bayesian approach offered important advantages over optimization, including more effective explorative of the model space and more robust characterization of the spatial pattern of Rayleigh wave group velocity. Meanwhile, the iterative, least-square subspace optimization suffered from the subjectivity of choice for reference velocity model and regularization parameter values. Our Rayleigh wave group velocity results show that for short (1-10 s) periods group velocity correlates well with surface geology, and for longer periods (13-25 s) it correlates with centres of volcanic activity.
\end{abstract}

Key words: Asia; Tomography; Crustal structure; Seismic noise.

\section{INTRODUCTION}

The western part of Java lies near the centre of the Sunda Arc, where the Australian Plate subducts beneath the Eurasian Plate (Fig. 1a). It is a region of particular interest because it is near the transition between the oblique convergence off Sumatra, where the parallel component of subduction is mostly accommodated by the right-lateral Great Sumatran Fault running the length of Sumatra, to arc-normal convergence off Java (Malod et al. 1995). This transition in convergence obliquity coincides with a transition from relatively young (40-100 Ma) oceanic plate subducting off Sumatra, to relatively old (100-135 Ma) subducting plate off Java, with consequent steepening in the angle of subduction to $60^{\circ}-65^{\circ}$ beneath Java (Hamilton 1979; Widiyantoro \& van der Hilst 1996).

One important reason to study the crustal structure of Java is to improve our knowledge of geohazard risk there. Java is the most populated (over 140 million) and at the same time one of the most densely populated islands on Earth. Western Java, the area considered in this study, is home to $\sim 70$ million inhabitants living within an area of $\sim 45 \mathrm{~K} \mathrm{~km}^{2}$. This includes the world's 2nd largest contiguous urban area, the urban agglomeration of Jakarta, Bogor, Depok, Tangerang and Bekasi, with a population of 32 million (DEMOGRAPHIA 2018), as well as another of Indonesia's largest cities, Bandung, Greater Bandung having a population of over 11 
(a)
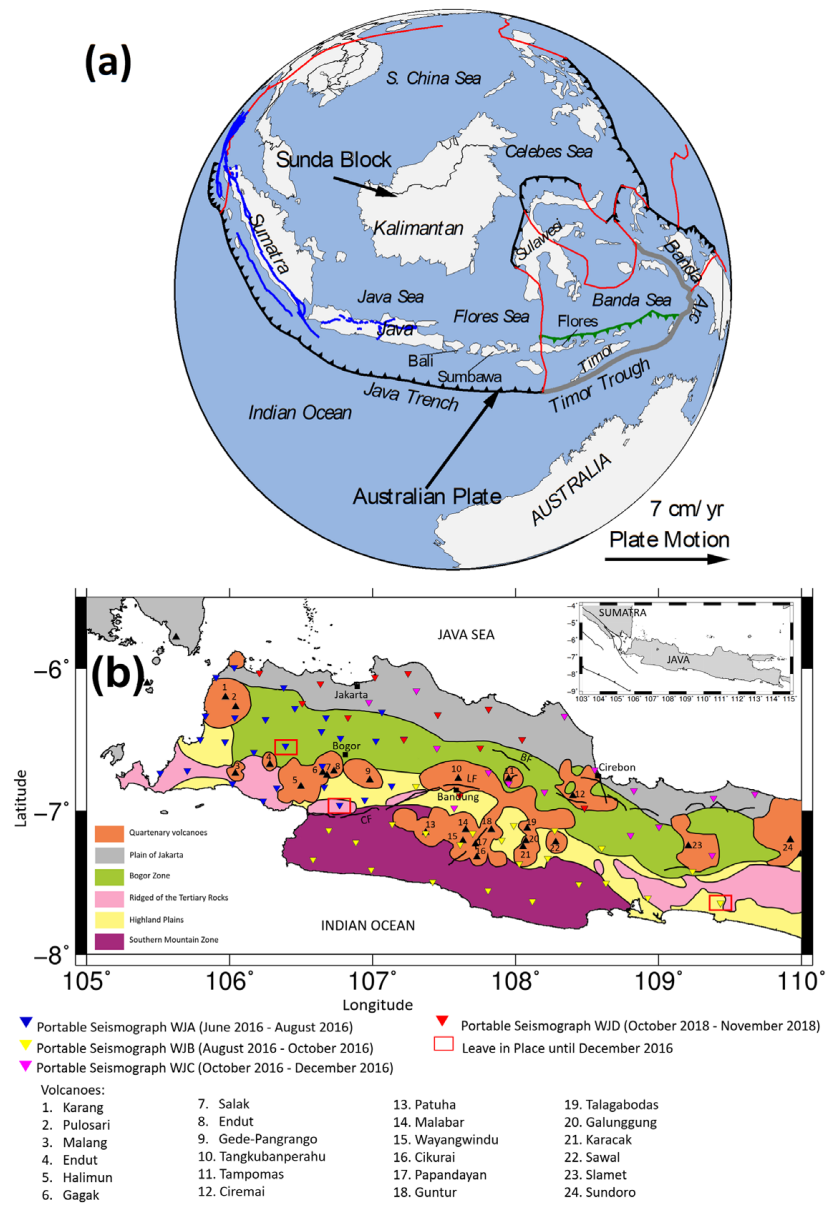

Figure 1. (a) Map showing major tectonic plate boundaries in Indonesia (from Bird 2003). (b) Physiography map (modified from van Bemmelen 1949) and station distribution in the study area. Inset in the top right corner shows the position of the western part of Java. In (b), volcanoes are shown by black triangles and stations are denoted by inverted red triangles. There are three major active faults in the western part of Java: CF (Cimandiri Fault), LF (Lembang Fault) and BF (Baribis Fault). We use the coordinate from the National Earthquake Study Centre (PUSGEN) (2017). The colour in inverted triangles shows the deployment period and area. Blue shows seismometers deployed in Banten (WJA), yellow shows seismometers deployed in the southern part of West Java (WJB), magenta shows seismometers deployed in the northern part of West Java (WJC), red shows the additional deployment in the northern part of West Java (WJD).

million. It is important to understand sources of seismicity and volcanic activity that may threaten this urban corridor since it includes a huge amount of residential construction as well as the infrastructure of crucial importance to Indonesia's economy.

Although no extensive damage has been caused by earthquakes in western Java since the beginning of the 20th century, historical accounts suggest the occurrence of such events during 1677-1844. Griffin et al. (2018) have shown that while several of these have occurred on crustal faults, in some cases where active faults have not been mapped. Active volcanoes are concentrated mainly in the middle and south of the area, between Bandung City and Southern Mountain Zones (Fig. 1b). To the north of Bandung lies Mt Tangkuban Perahu, which had a phreatic eruption in 2013, and Mt Tampomas. To the south of Bandung, there are Mt Kendeng, Mt Patuha, Mt Malabar, Mt Papandayan Mt Guntur (last eruption in 1847) and Mt Cikurai, which separate Bandung from the city of
Garut. Mt Galunggung, which had a major eruption in 1982, together with Mt Karacak, Mt Talaga Bodas lie between Garut and the city of Tasikmalaya. In the northern part, the coastal plain of Jakarta which composed of alluvial and young volcanic deposits extends from west to east (van Bemmelen 1949).

By improving the resolution of seismic velocity structure in the upper crust of western Java, we can facilitate precise hypocentre and focal mechanism estimation (see, e.g. Hejrani et al. 2017; Nugraha et al. 2018) and provide useful initial models for fine-scale seismic tomography studies to delineate seismogenic areas and magmatic plumbing of active volcanic systems (see, e.g. Widiyantoro et al. 2018). Improved models of the crust's seismic velocity structure also support the development of Indonesian earthquake ground motion models, which are essential for improving seismic hazard assessment (Ridwan et al. 2019).

In order to image the upper crustal velocity structure beneath the western part of Java, we applied the ambient noise tomography (ANT) method to data from a large-scale temporary seismograph deployment. The ANT method is based on the principle of seismic interferometry, introduced by Claerbout (1968) whose paper spurred the development of the technique for seismic application. Seismic interferometry generally refers to the extraction of empirical Green's functions (EGFs) through the cross-correlation of ambient seismic noise recorded simultaneously at a pair of seismographs (Lobkis \& Weaver 2001; Shapiro \& Campillo 2004; Larose et al. 2006; Snieder \& Larose 2013). Some of the previous studies using the ANT method have successfully imaged structure beneath New Zealand (Lin et al. 2007), the northwestern United States (Gao et al. 2011), Australia (Saygin \& Kennett 2012), Central Java (Zulfakriza et al. 2014), Jakarta (Saygin et al. 2016), Bandung Basin (Pranata et al. 2016), East Java (Martha et al. 2017) and south of West Java (Rosalia et al. 2019).

The first step in determining crustal seismic velocity structure with ANT is to estimate the spatial variation of group velocity at selected periods. This estimation must deal not only with the strongly non-linear relationship between dispersion curves and group velocity parameters, but also with the invariably mixed over/underdetermined character of the inverse problem. Broadly considered, there are two approaches to non-linear inverse problems: optimization with regularization, and probabilistic sampling, targeted at an objective function representing a misfit or likelihood. In this study, we consider two specific methods, each representative of one of these approaches: for optimization, we use the least-squares subspace method (FMST, see Rawlinson et al. 2006) and for probabilistic sampling, we use a transdimensional Bayesian method (Trans-D, see Hawkins \& Sambridge 2015). We will discuss the group velocity maps obtained from both inversion methods and discuss their relative merits as applied to the inversion of crustal group velocity maps for western Java.

\section{DATA}

The data used in this study are continuous seismic waveform data recorded from the 2016 deployment, which we hereafter refer to as the ITB-ANU Network. We installed 27 portable seismometers in three areas of the western part of Java (Fig. 1b). The ITB-ANU Network consists of three phases deployment: WJA, WJB and WJC. We first deployed the instruments in the Banten area (WJA) and then moved them to the southern part (WJB) and finally to the northern part of western Java (WJC). The instrument deployments for WJA, WJB and WJC began in June 2016 and ended in December 2016 
with a span of 2-8 weeks for each installation. An additional 15 stations (WJD) were deployed in October-November 2018 to improve coverage of the northern part of the study area. In total, we have deployed 85 stations in western Java. The instruments used in this research are Nanometrics Trillium Compact seismometers, with recorders produced by the Australian National University (ANU) that use GPS for time synchronization and SD-card as storage media. Each station was deployed in a school, governmental building or residential house to ensure the security of the instruments. The deployment ran with a sampling rate of $250 \mathrm{~Hz}$ and the distance between stations varies from about $20 \mathrm{~km}$ to over $300 \mathrm{~km}$.

Before doing the data processing, we assess our waveform data quality, paying especial attention to accurate timing. Accurate timing of seismograms is crucial for the cross-correlation processing in ANT to produce accurate EGFs. Hence, in their ANT study of La Réunion, Hable et al. (2018) investigated and corrected clock errors in land and ocean bottom seismograms by utilizing crosscorrelograms of ambient noise for each day. If the day by day result of interstation cross-correlation shows a shift in its peak, it suggests a timing error at one of the stations, and by comparing these shifts at multiple station pairs, time corrections for individual stations can be determined.

We applied the method of Hable et al. (2018) to our data sets by computing daily waveform cross-correlations between two nearby stations and examining them over successive days. An example of such a set of daily cross-correlograms between ITB-ANU network stations WJA01 and WJA02, with an interstation distance of $23.35 \mathrm{~km}$, appears in Fig. S1. We applied a long period multifilter band of $10-20 \mathrm{~s}$ and $20-50 \mathrm{~s}$ to the data. The result in Fig. S1 shows a very stable alignment of cross-correlation peaks across all days of the deployment, which suggests there is an accurate time base that needs no correction. We obtained similar results for all station pairs of the ANU-ITB network. Note that we also considered including data from the permanent Indonesian seismograph network operated by the Indonesian Agency for Meteorology, Climatology and Geophysics (BMKG). We found that the BMKG waveform data included many gaps that made it difficult to compute cross-correlations, so we did not include the BMKG network data in this study.

\section{METHODS}

We utilized the waveform of the vertical component and followed the ANT processing method described by Bensen et al. (2007) and Yao et al. (2006) to obtain Rayleigh wave EGFs for all available station pairs. We converted the miniseed files from each station to SAC format, removed the instrument response, resampled the data to $10 \mathrm{~Hz}$ and then applied demeaning, detrending, one-bit time domain normalization, and bandpass filtering to reduce any earthquake signals recorded by the instruments. We calculated the crosscorrelation for daily time-series and stacked the results to produce the EGFs. EGFs extracted from interstation pairs give information about the surface wave traveltime and dispersion between the stations. The cross-correlograms provide clear surface wave signals (Fig. 2). The EGFs are often asymmetrical, more clearly evident in the acausal part of the correlogram, especially at larger interstation distances. Based on Wapenaar (2003), Wapeenar et al. (2005) and Snieder (2007), the formulation of Green's function extraction assumes homogeneously distributed surface sources. However, the real distribution of background seismic energy depends on ocean waves and their coupling to the subsurface. Hence, the asymmetry of the cross-correlation time-series suggests that ambient noise
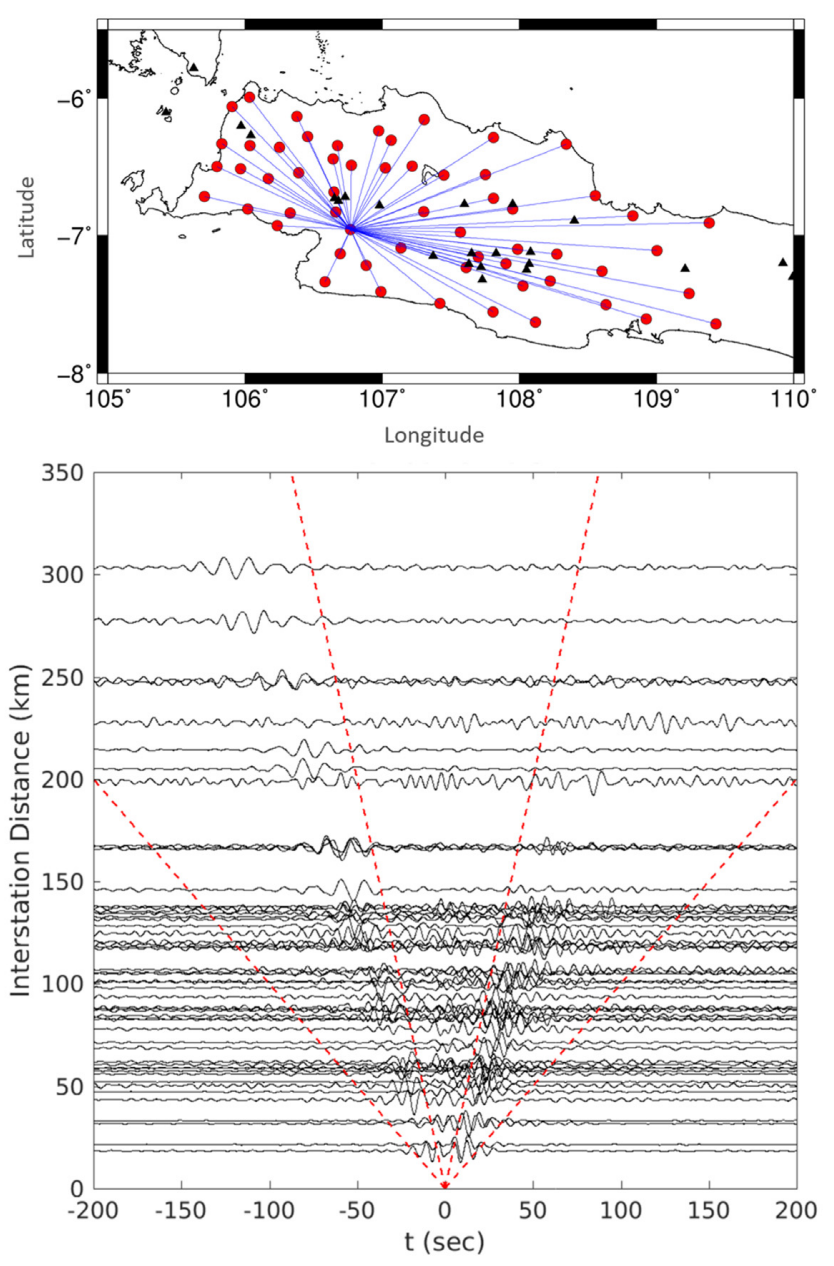

Figure 2. Rayleigh wave EGFs between the station in the centre of area study, WJA03 to other stations. Waveforms were filtered between 0.05 and $0.2 \mathrm{~Hz}$. Red line shows the group velocity window of EGFs for estimating the amplitude of the signal.

sources are not evenly distributed. The most energetic seismic noise source of the ambient noise in this study area is in the acausal part which can be inferred to be from the north, in the direction of the Java Sea. The finding is in a good agreement with a previous study in Central Java (Yudistira \& Widiyantoro 2016).

We applied the dispersion curve analysis procedure of Yao et al. (2011) using a traditional frequency-time analysis with a multiple filtering technique (Dziewonski et al. 1969) to obtain the group velocity by picking the maximum amplitude in the period range 1-30 s. We selected the highest quality dispersion curves based on a minimum EGF signal-to-noise ratio (SNR) of 10 and a minimum inter-station path length of 1.5 wavelengths. Although Yao et al. (2006) recommend that an interstation distance should be at least two wavelengths, Porritt et al. (2016), in their ANT study of the Banda Arc, showed that the length of 1.5 wavelengths also could be used to account for the number and coverage of raypaths. The example of the dispersion curve of WJB07-WJB20 which is selected using the criteria above is shown in Fig. 3. It shows a good and clear dispersion curve with SNR $>10$. For that station pair, we saved the final dispersion points from period 1-24 s based on the 1.5 wavelengths criteria. From a total of 974 EGFs calculated by inter-station cross-correlation, we obtained 449 good quality dispersion curves to be used for the inversion of group velocity maps (Fig. 4). 

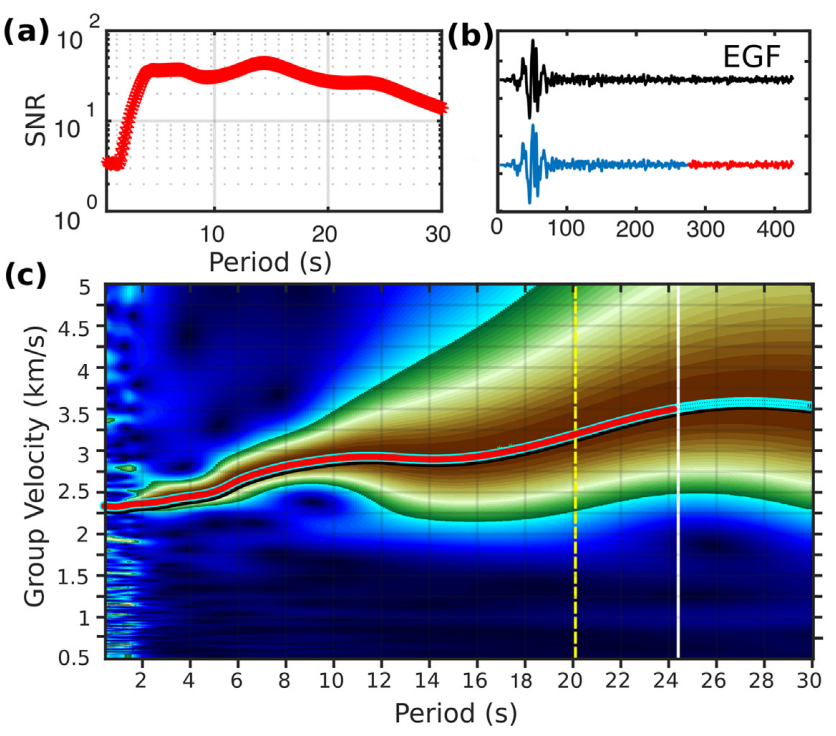

Figure 3. Group velocity dispersion analysis from station pair WJB07WJB17 (c) which has SNR > 10 (a) and clear EGF (b). The top black trace in (b) is the symmetric component of the EGF and the bottom blue colour is the signal part and the red colour is the noise part to calculate the SNR. The yellow dashed line shows the station distance $>2$ wavelengths and the white line shows the station distance $>1.5$ wavelengths, which used in this study. Brown and blue colours show for high and low amplitudes. The red line represents the final periods saved for group velocity dispersion data and the blue open circles represent the periods with SNR $>10$. We picked the clear dispersion curve from 1 to $24 \mathrm{~s}$.

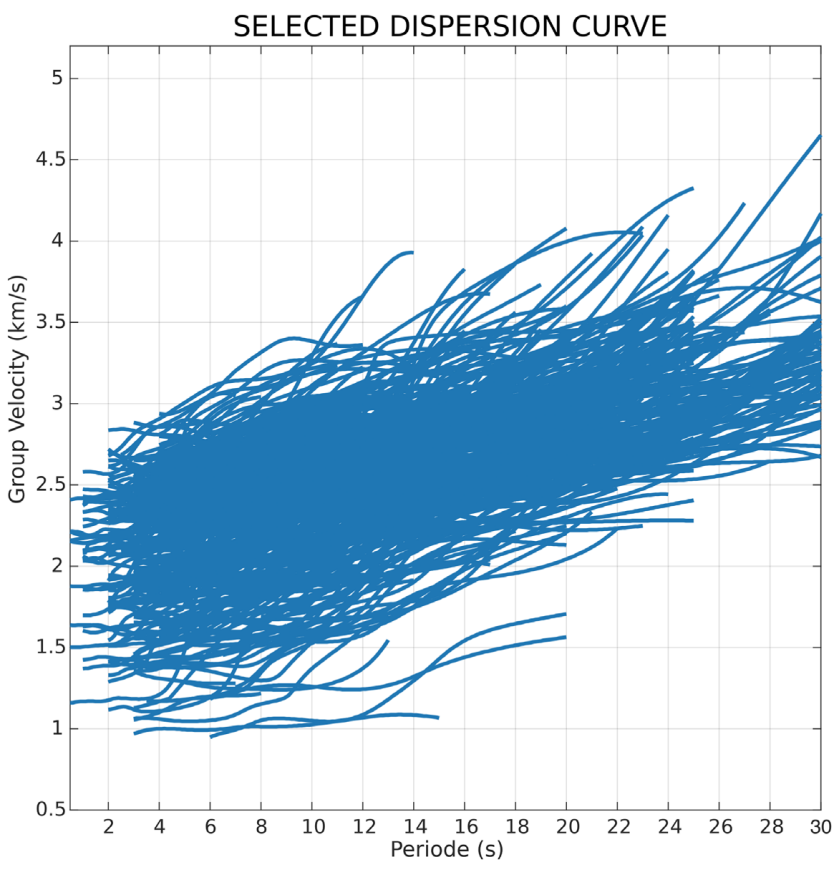

Figure 4. Selected dispersion curve from 1 to $30 \mathrm{~s}$ used in the study. The group velocity ranged from 1 to $4.5 \mathrm{~km} \mathrm{~s}^{-1}$.

To obtain the group velocity map in each period, we applied two inversion methods, a conventional subspace (FMST) inversion and the Trans-D Bayesian inversion. Both methods used the same algorithm for the traveltime calculation which is the fast marching method (FMM; Sethian 1999; Rawlinson \& Sambridge 2005). The FMM is an eikonal solver that tracks the wave fronts over a grid using a finite difference solution. FMM offers robust solutions for wave propagation, even in highly heterogeneous media. Because both methods used the same forward model calculation, we can reasonably compare the methods.

\subsection{Subspace inversion using FMST}

Subspace inversion is an iterative method in which an objective functional is minimized by using successive quadratic approximations of the function in an $n$-dimensional subspace (Kennett et al. 1988). Once the minimum of the quadratic approximation is found in the model subspace, a new quadratic approximation is made, either in the same or a different model subspace, and the process repeated. At each step, the rays are retraced using FMM, so the nonlinear relationship between velocity and traveltime is accounted for. The method has been successfully applied to obtain the group velocity structure in various regional studies (Saygin \& Kennett 2012; Martha et al. 2017). Regularization using damping and smoothing is needed to stabilize the inversion, and in addition to dependence on regularization parameters, it also requires a fixed parametrization (i.e. grid size), and in principle depends also on the initial model and the number of iterations.

From Saygin \& Kennett (2012), the misfit function to be minimized for each period is:

$$
\begin{aligned}
\phi(\boldsymbol{m})= & (\boldsymbol{g}(\boldsymbol{m})-\boldsymbol{d})^{T} \boldsymbol{C}_{e}^{-1}(\boldsymbol{g}(\boldsymbol{m})-\boldsymbol{d})+\epsilon\left(\boldsymbol{m}-\boldsymbol{m}_{0}\right)^{T} \boldsymbol{C}_{m}^{-1} \\
& \times\left(\boldsymbol{m}-\boldsymbol{m}_{0}\right)+\eta \boldsymbol{m}^{T} \boldsymbol{D}^{\boldsymbol{T}} \boldsymbol{D} \boldsymbol{m},
\end{aligned}
$$

where $\boldsymbol{m}$ is a vector of model parameters (i.e. the group velocity map), $\boldsymbol{g}(\mathbf{m})$ are the predicted group traveltimes from the model, $\boldsymbol{d}$ are the observed group traveltimes, $\mathbf{C}_{\mathrm{e}}$ is the data error covariance matrix, $\boldsymbol{m}_{0}$ is the reference model, $\mathbf{C}_{\mathrm{m}}$ is the model parameter covariance matrix, $\mathbf{D}$ is a flatness/smoothness matrix, $\varepsilon$ is the damping parameter and $\eta$ is the smoothing parameter. We take $\mathbf{C}_{\mathrm{e}}=\mathrm{I} \sigma^{2}$, so that errors are assumed uncorrelated and follow a Gaussian distribution with zero mean and standard deviation $\sigma$, which is taken to have the value $1 \mathrm{~s}$. As reference model $\boldsymbol{m}_{0}$, we chose a uniform Rayleigh wave group velocity of $2.25 \mathrm{~km} \mathrm{~s}^{-1}$. To choose the damping and smoothing factor, we used the 'L-curve' test that trades off data misfit with model variance and roughness, as shown for $5 \mathrm{~s}$ period in Fig. 5. We varied the damping factor $\epsilon$ from 0 to 1000 and plotted the traveltime misfit and model variance for each period. Based on this test, the best value of $\epsilon$, which produces a good data fit and small model variance, is 10 . We did the same analysis for the smoothing factor $\eta$, but instead of model variance, we used the model roughness. We chose 25 as the best value for $\eta$.

The model vector $\boldsymbol{m}$ is parametrized as group velocity values at points on a rectangular grid that covers the study area. To assess what grid spacing should be used for $\boldsymbol{m}$, we conducted a checkerboard resolution (CKB). We used a homogeneous velocity model with perturbations of 35 per cent from the initial velocity model having a uniform velocity of $2.25 \mathrm{~km} \mathrm{~s}^{-1}$. We used various grid sizes of $60 \times 60 \mathrm{~km}, 30 \times 30 \mathrm{~km}$ and $15 \times 15 \mathrm{~km}$ to determine which size can be resolved in the study area, as shown in Fig. 10. From the CKB test, we can see that the $60 \times 60 \mathrm{~km}$ grid size can recover the initial velocity model, although this may not be the finest resolution attainable with the data set. The CKB test result for a $15 \times 15 \mathrm{~km}$ grid size produces smearing in the inversion result, so it appears out data set cannot resolve structure at this scale. The CKB test for a $30 \times 30 \mathrm{~km}$ grid size, on the other hand, achieves acceptable recovery of the initial velocity model where ray path coverage is high, so it is the most suitable for a target resolution in inverting the 

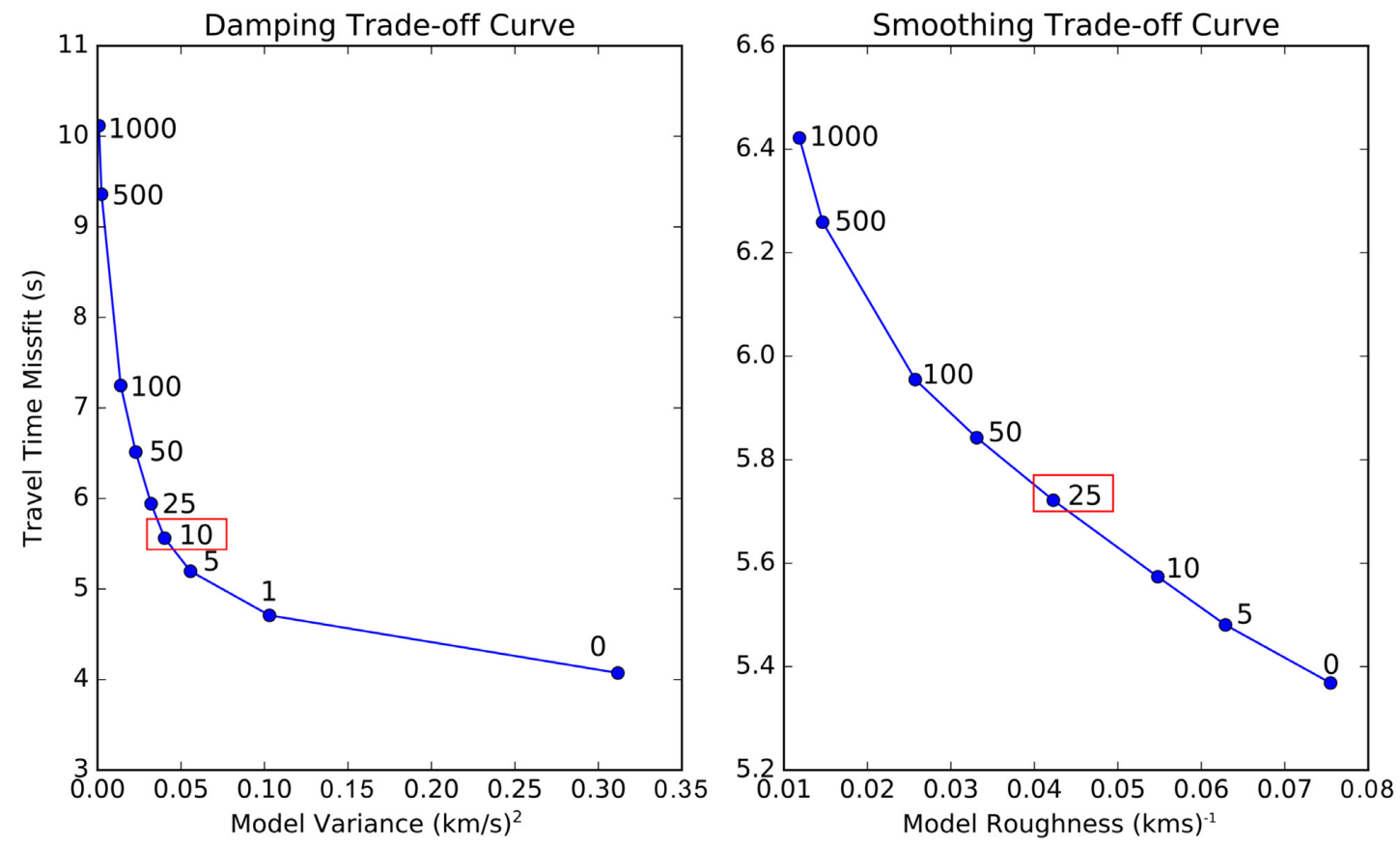

Figure 5. Damping and smoothing trade-off curve of period $5.0 \mathrm{~s}$. We varied the value from 0 to 1000 . The best value is the one that gives a good data fit and small variance (red box).

Initial Velocity Model
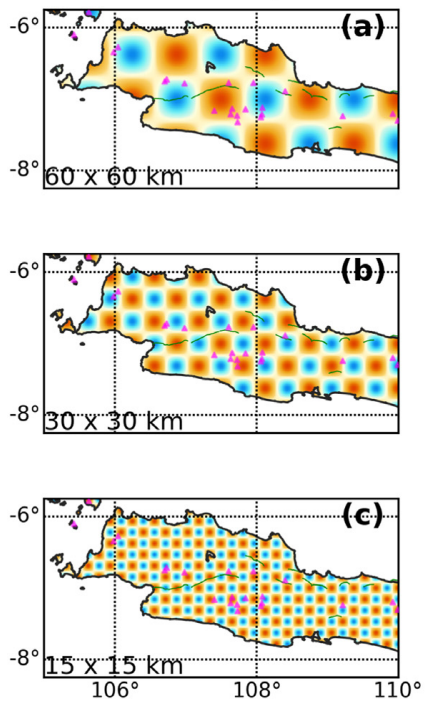

FMST
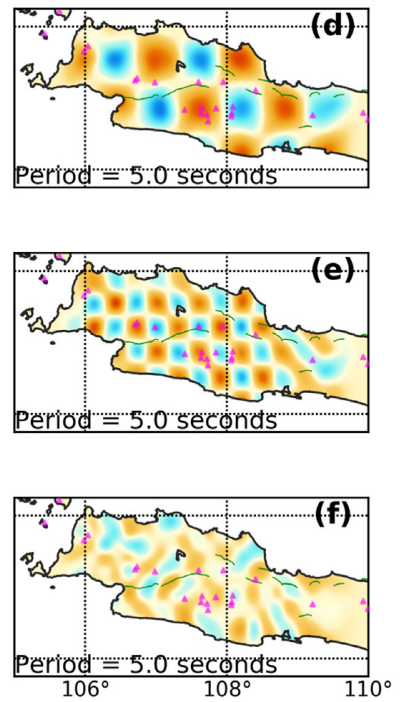

TransD
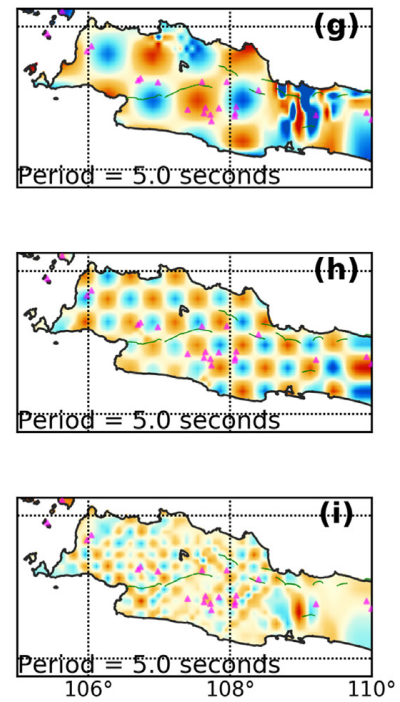

○

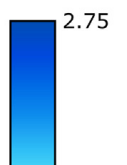

Figure 10. The checkerboard test result of FMST $(\mathrm{d}-\mathrm{f})$ and Trans-D $(\mathrm{g}-\mathrm{i})$ with its corresponding initial velocity model (a-c). We added 35 per cent perturbation from the initial velocity model of $2.25 \mathrm{~km} \mathrm{~s}^{-1}$ and varied the grid size of $60 \times 60 \mathrm{~km}$ (a), $30 \times 30 \mathrm{~km}$ (b) and $15 \times 15 \mathrm{~km}(\mathrm{c})$.

data. Fig. 6 shows the CKB test results for selected periods and a grid size of $30 \times 30 \mathrm{~km}$. The complete $\mathrm{CKB}$ results for each period are available in the supplementary document (Fig. S2).

Fig. 7 shows the results of subspace inversion of our ANT dispersion curves for Rayleigh wave group velocities at selected periods (results for all periods are shown in Fig. S4 and results for using straight rays are shown in Fig. S8). An intuitive grasp of the ability of our ANT data to resolve spatial variations of Rayleigh wave group velocity in western Java can be obtained by inspecting the ray path coverage shown in the right panels of Fig. 7. These show that at $1 \mathrm{~s}$ and greater than $20 \mathrm{~s}$ period, ray path coverage is relatively sparse. However, for periods between 3 and $20 \mathrm{~s}$, the density of ray paths increases considerably, which is in good agreement with the CKB test results in Fig. 6, showing good recovery of the $30 \times 30 \mathrm{~km}$ checkerboard pattern for the same period range. From the ray path coverage and $\mathrm{CKB}$ test, we can also see that there is poor ray path coverage along the easternmost part of the study area, and along its western tip and parts of the northern and southern coasts. However, most of the study area has good ray path coverage and is well resolved for periods 3-20 s. 

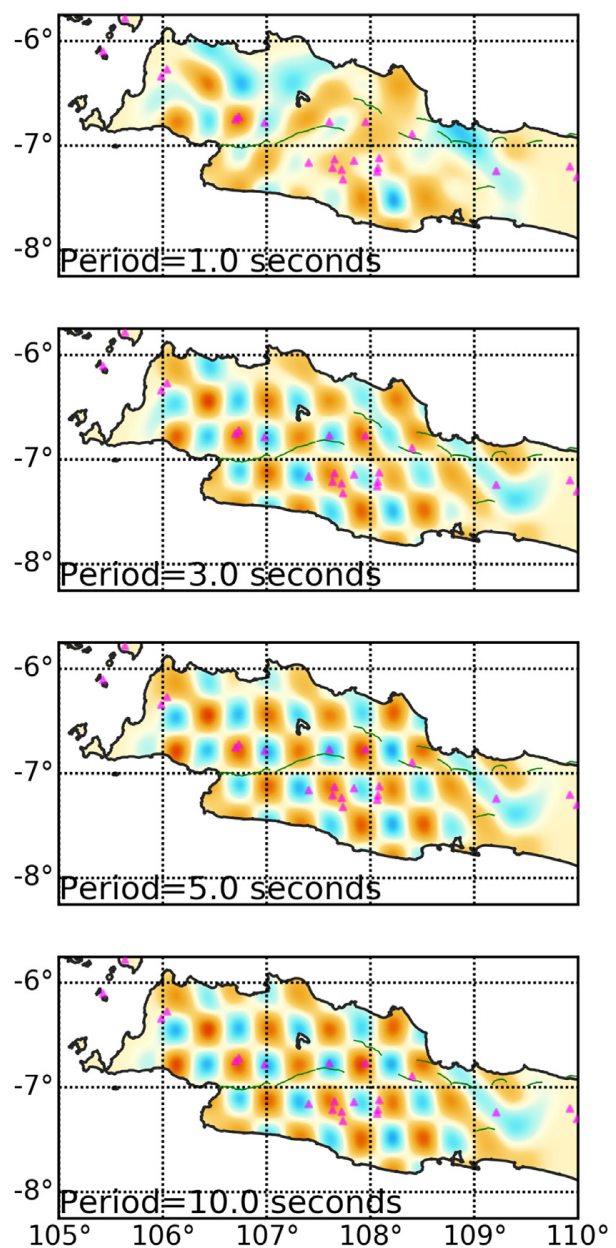
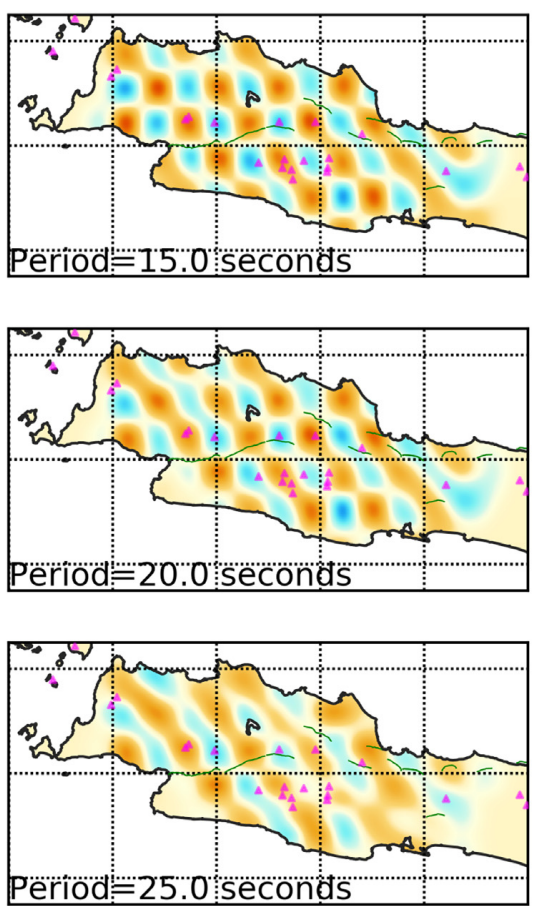

2.50

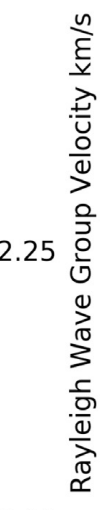

2.00

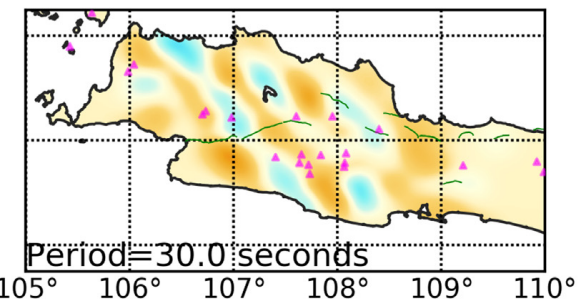

2.75

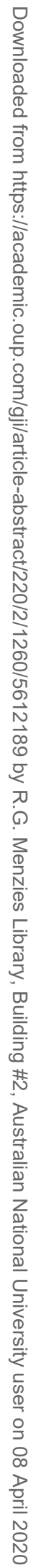

where the evidence in the denominator is again regarded as a normalization constant that can be ignored in the probabilistic sampling of $P\left(k, \boldsymbol{m}_{k} \mid \boldsymbol{d}\right)$. Sampling of the a posterior probability (eq. 4) can be undertaken using the Reversible Jump Markov chain Monte Carlo (RJMcMC) algorithm, a procedure referred to as 'transdimensional' (Trans-D) sampling that was introduced to geophysics by Malinverno (2002). RJMcMC sampling is the basis for the Trans-D Bayesian inversion that has been successfully applied to a number of geophysical inverse problems (Sambridge et al. 2006; Agostinetti \& Malinverno 2010; Minsley 2011; Dettmer et al. 2012, among others).

In previous tomographic studies, the Trans-D method with

Voronoi cell parametrization (Bodin \& Sambridge 2009; Bodin et where $P\left(\boldsymbol{m}_{k}\right)$ is the a priori probability of the model expressing the information available about the likelihood of the model $\boldsymbol{m}_{k}$ before the measurement of data $\boldsymbol{d}$, and $\int P\left(\boldsymbol{d} \mid \boldsymbol{m}_{k}^{\prime}\right) d \boldsymbol{m}_{k}^{\prime}$ is the probability usually regarded as a normalization constant and can be ignored in the probabilistic sampling of $P\left(\boldsymbol{m}_{k} \mid \boldsymbol{d}\right)$.

Green (1995) showed how Bayes' Theorem could be used to express not only the conditional probability for a model $\boldsymbol{m}_{k}$ having a fixed parametrization $k$, but also the probability that the model has any one of a countable set of different parametrizations expressible

$P\left(k, \boldsymbol{m}_{k} \mid \boldsymbol{d}\right)=\frac{P\left(\boldsymbol{d} \mid \boldsymbol{m}_{k}\right) P(k) P\left(\boldsymbol{m}_{k}\right)}{\sum_{k^{\prime}} \int_{\boldsymbol{m}^{\prime} k^{\prime}} P\left(\boldsymbol{d} \mid \boldsymbol{m}_{k^{\prime}}\right) d \boldsymbol{m}_{k^{\prime}}^{\prime}}$,

where $\left|\boldsymbol{C}_{e}\right|$ is the determinant of the data error covariance matrix, could now be used with Bayes' Theorem to express the a posterior conditional probably distribution function (PDF) for the model $\boldsymbol{m}_{k}$ given the data $\boldsymbol{d}$ :

$P\left(\boldsymbol{m}_{k} \mid \boldsymbol{d}\right)=\frac{P\left(\boldsymbol{d} \mid \boldsymbol{m}_{k}\right) P\left(\boldsymbol{m}_{k}\right)}{\int P\left(\boldsymbol{d} \mid \boldsymbol{m}^{\prime}{ }_{k}\right) d \boldsymbol{m}^{\prime}{ }_{k}}$, 

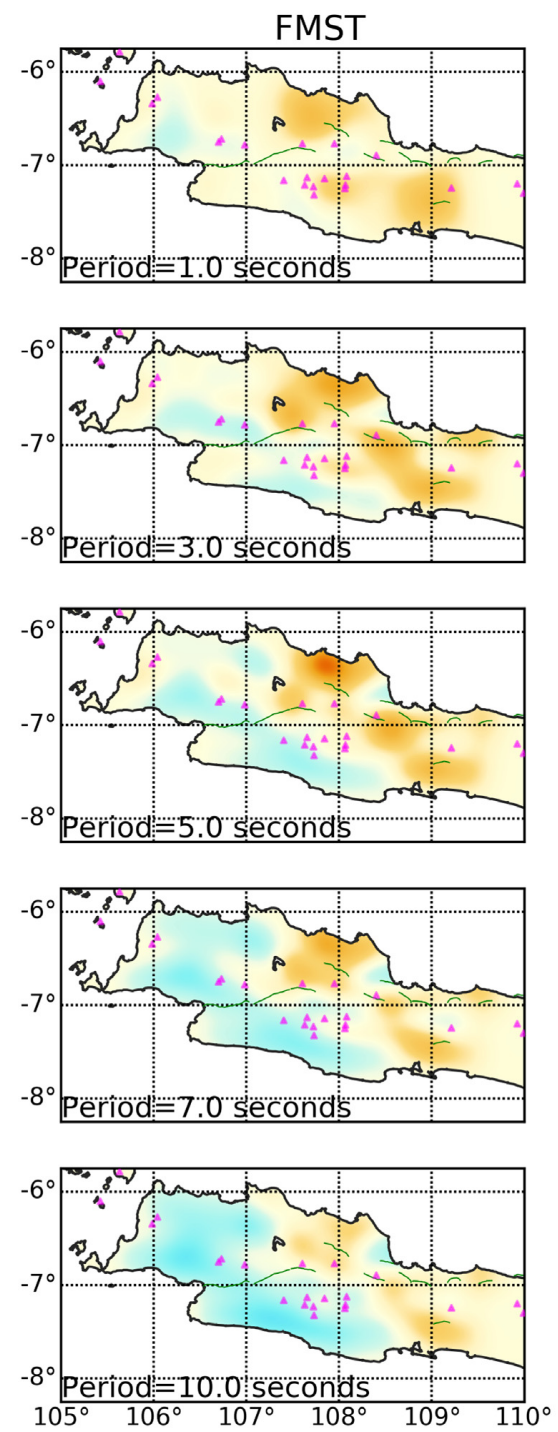
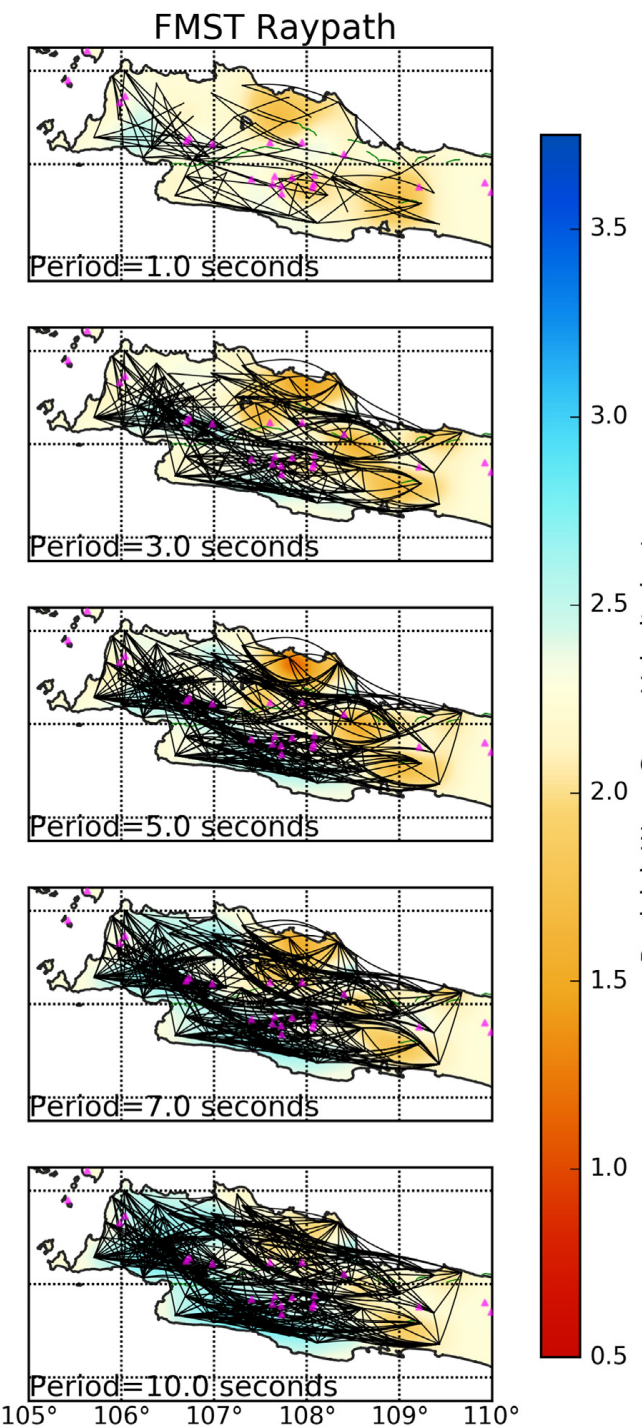

Figure 7. Tomography result from period 1-25 s using the FMM for forward modeling to calculate the traveltimes and subspace inversion to obtain the subsurface image beneath the western part of Java (left-hand picture) and its ray paths (right-hand picture). Red colour indicates low group velocity and blue colour indicates high group velocity. The green line is the active fault in West Java and the magenta triangle is the active volcano.

al. 2012) has been successfully applied to obtain the velocity structure in various regional studies (Young et al. 2011; Zulfakriza et al. 2014; Pilia et al. 2015; Saygin et al. 2016). In this study, the TransD Bayesian method developed by Hawkins \& Sambridge (2015), which utilizes a tree-based wavelet parametrization (Fig. 8a), was applied to a surface wave group velocity measurement of our western Java ANT study. Details of the method and implementation are described in Hawkins \& Sambridge (2015). This Trans-D Bayesian with a tree-based wavelet parametrization, hereafter referred to as 'Trans-D Tree', has been applied to teleseismic body wave data in South Australia and synthetic data for ANT (Hawkins \& Sambridge 2015), as well as to the inversion of tsunami waveforms for initial sea-surface displacement (Dettmer et al. 2016). These studies show the Trans-D Tree method to be efficient and flexible because of the utilization of wavelet parametrization for mapping to and from regular grids, and the construction of multiscale models in a top-down, coarse-to-fine-scale fashion.

Since FMST and Trans-D Tree both use the FFM for the forward model, the difference of the two methods is in the adaptability of the Trans-D Tree method. In contrast to FMST, the equivalent to tuning parameters in Trans-D Tree is the prior on the wavelet coefficients. The Trans-D Tree method adapts both the mean velocity, which is the analogue to the reference velocity, and the smoothness, which relates to the number of wavelet coefficients, through the hierarchical prior. The number of wavelet coefficients in effect acts like smoothing, with fewer coefficients resulting in a smoother model. However, unlike the global smoothing applied in FMST, Trans-D Tree can use many coefficients to represent fine-scale heterogeneity in well-resolved parts of the model and vice versa, so smoothing over the model domain is spatially variable and adapts to the data. Also, rather than set the smoothing to a single value (as in FMST), we sample over many reasonable numbers of coefficients to get a probabilistic answer as to how smooth the estimated model is.

The hierarchical prior automatically adapts the prior width on the wavelet coefficients in an attempt to remove any bias in the final result caused by setting too wide or too narrow a prior. Trans-D Tree's hierarchical error scaling (i.e. adjusting the value of $\sigma$ in the matrix $\boldsymbol{C}_{e}$ of eq. 3) allows the data to decide what level of error is appropriate. Without the hierarchical adjustment of the error, if the estimated errors are too large, the final result may not reflect 
FMST
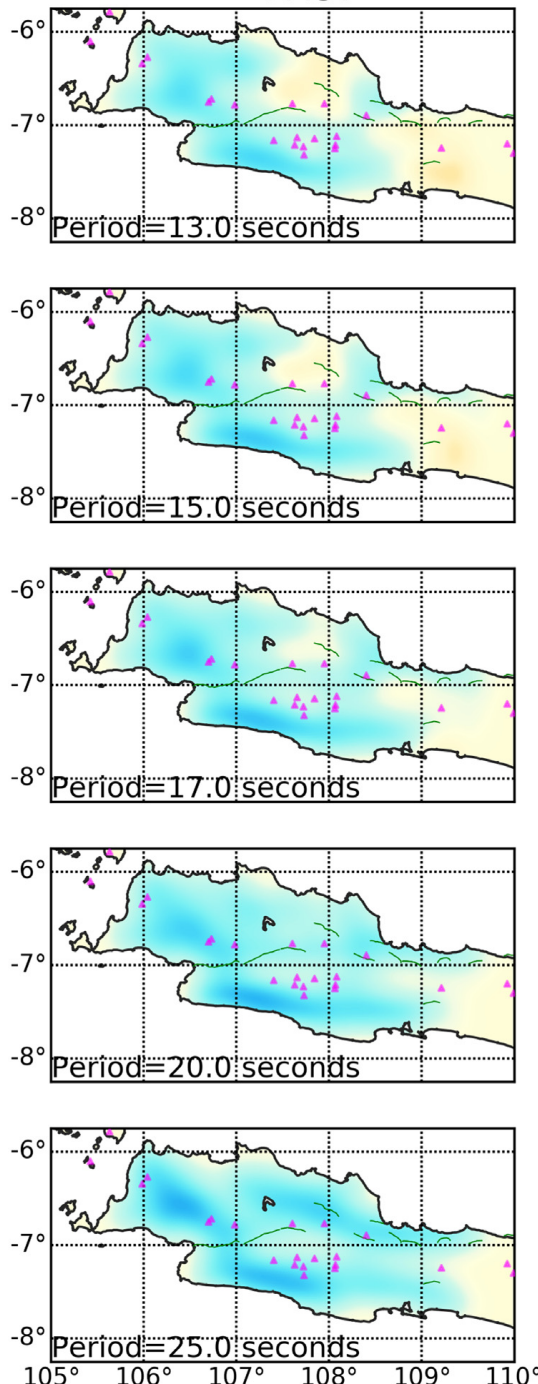

Figure 7. (Continued.)

(a)

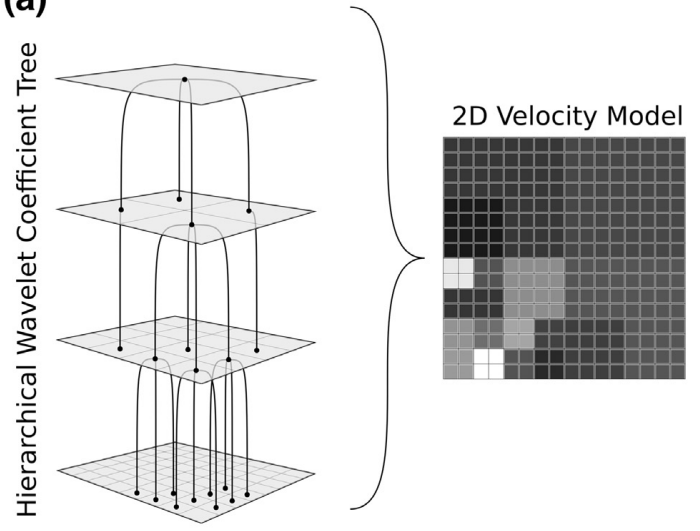

FMST Raypath
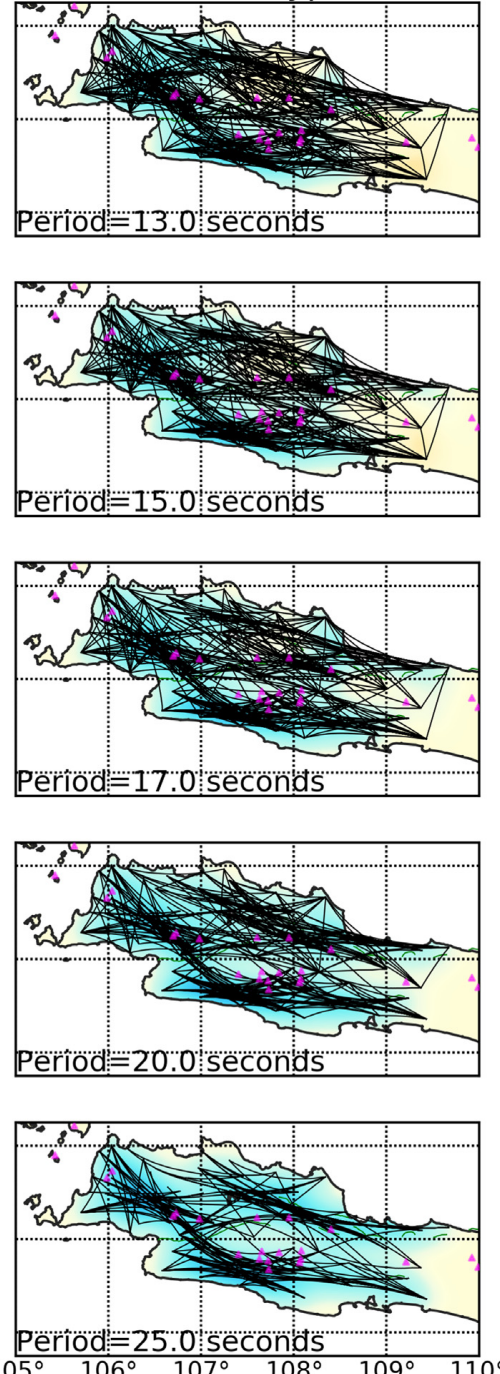

3.5

3.0

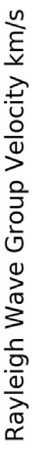
1.5

0.5

Figure 8. (a) Tree structure for wavelet coefficients. (b) The effect that using a Laplacian prior for the Cohen-Daubechies-Feauveau wavelet coefficients has

on the mean group velocity values for various values of the width.

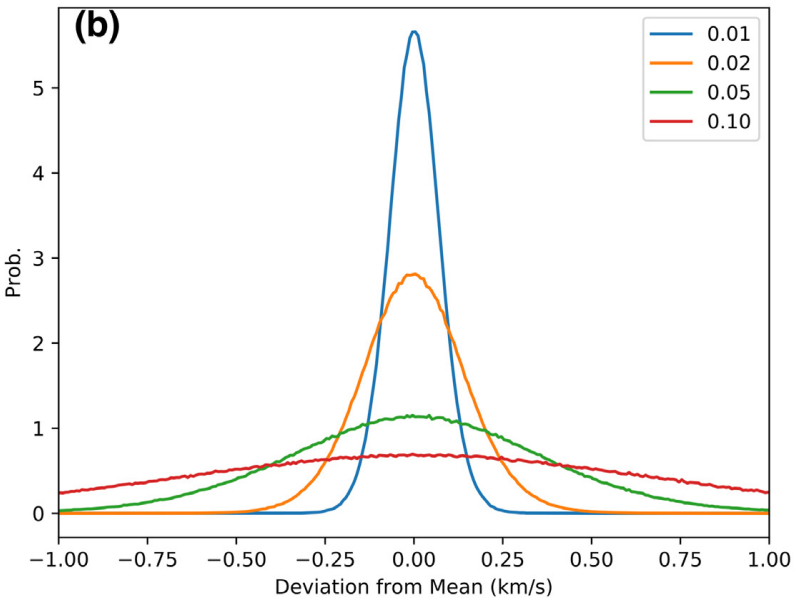


the information content of the data (e.g. it may be too smooth), and if the estimated errors are too small, the final result may have spurious structure that is not required by the data (i.e. 'fitting the noise'). The hierarchical error interacts with the Trans-D Tree model dimensional complexity so that the final result, model plus data errors, is a balance between fitting the data and having reasonable error estimates. In FMST by contrast, this is all controlled by the damping and smoothing parameters.

The Trans-D Tree inversion with hierarchical errors and hierarchical prior then has far fewer control parameters and therefore less sensitivity to user input such as the reference model or values for $\epsilon$ and $\eta$ (eq. 1). Both the standard deviation of the error $\sigma$ and the model complexity (as indexed by $k$ ) are allowed to adapt to the data in a way that produces a 'parsimonious' solution that does not introduce more model complexity than is required by the data (Malinverno 2002).

Although the prior $P\left(\boldsymbol{m}_{k}\right)$ is used to express prior information on the likelihood of Rayleigh wave group velocity values, the treebased wavelet parametrization requires that the prior be specified in terms of wavelet coefficients. Because the tree structure forms a multiresolution hierarchy in which finer-scale wavelets are perturbations to a coarser-scale wavelet basis (see Fig. 8a), the relationship between wavelet coefficients and velocity is not obvious. In this study, we use a prior $P\left(\boldsymbol{m}_{k}\right)$ on wavelet coefficients that is a Laplacian distribution having a width of 0.2 that is suitable for a 7-level wavelet hierarchy that describes group velocities in the range of about $3.0 \pm 1.0 \mathrm{~km} \mathrm{~s}^{-1}$ (see Fig. 8b, and Hawkins et al. 2018). The wavelet-basis used was the Cohen-Daubechies-Feauveau 9/7 wavelet (Cohen et al. 1992).

We used both linearized (straight rays) inversion and non-linear (rays traced with FMM) inversion, with the final model from the linearized Trans-D inversion used as the starting model for the non-linear inversion. The motivation for using the linear result for initializing the non-linear inversion is to save computation time in converging the non-linear inversion. The assumption is that the linear inversion is a reasonable approximation of the physics and therefore a reasonable starting position. Although the linearized inversion can calculate the forward model quickly, the FMM is useful when strong lateral heterogeneity is present, as we might expect for shallow crustal structure in western Java.

The RJMcMC sampling method used here included multiple chains and Parallel Tempering in order to improve the exploration of the model space and accelerate convergence (see, e.g. Sambridge 2014). We use two chains at each of three temperatures and attempt to exchange information between adjacent pairs of temperatures at every 10th step. For the linearized inversion, we ran 1500000 Markov chain steps for each chain and period, while for the nonlinear inversion, we ran between 200000 and 400000 steps for each chain and period, with the length depending on whether visual inspection of the chain histories (see Fig. 9) indicated that convergence had been achieved. We assumed the first half of the chain steps as the burnin samples (skipped) and the last half of the chain steps as the post-burnin to compute the mean model. We used half of the chain because we assumed that as we run chain steps long enough, the last half of the chain could be used to compute the mean model.

The Trans-D inversion's Markov chains can be assessed for convergence by visual inspection of the histories of diagnostic parameters like the likelihood and $\sigma$, the standard deviation of the data error distribution. Fig. 9 shows these histories for the last 180000 steps of the Markov chains for selected periods, along with maps of the average Rayleigh wave group velocities calculated over the Markov chain ensemble. (pre-convergence 'burn-in' is mainly confined to the linearized inversions, which are not shown). The chain histories for the negative log likelihood and $\sigma$ appear to exhibit random fluctuations about a value that is constant over the chain history. While convergence of Markov chains is difficult to establish conclusively, we regard this 'flat' character of the chain histories as a good indication that they have converged. As a comparison, we plotted the full chain histories in Fig. S6.

\section{COMPARISON OF SUBSPACE AND TRANS-D INVERSIONS}

The Trans-D Bayesian approach to inversion described above is much more computationally demanding than the subspace inversion, but provides an a posteriori PDF that allows for rigorous error appraisal and description of the spatial variation in group velocity using properties of the PDF such as its mean or median, that are robust in the sense that they depend on an aggregation over many models (and, in the Trans-D case used here, many model parametrizations). The subspace inversion, on the other hand, is an optimization that finds a single model that best fits the data using a particular parametrization subject to regularization.

We perform the same CKB test of the subspace using Trans-D inversion as comparison for the synthetic data inversion. The results are shown in Figs 10(g)-(i). The Trans-D result for $60 \times 60 \mathrm{~km}$ grid (Fig. 10g) shows a good reconstruction except in the east part where there is lack of ray path. The Trans-D result for $30 \times 30 \mathrm{~km}$ grid (Fig. 10h) shows a good reconstruction of the initial velocity throughout the study are. Meanwhile, the Trans-D result for $15 \times 15 \mathrm{~km}$ grid (Fig. 10i) shows better reconstruction than the FMST which prove that the FMST suffer from grid size parametrization.

A comparison of the results we obtained using Trans-D Bayesian and subspace inversion for real data is shown in Fig. 11 for group velocity at $20 \mathrm{~s}$ period. Figs 11 (a) and (b) shows the lower and upper bounds, respectively, of the 95 per cent credibility interval, which has a width of $1-2 \mathrm{~km} \mathrm{~s}^{-1}$. These credible intervals are calculated from the ensemble which could provide estimate of the uncertainties. The 95 per cent credible intervals mean that we have a 95 per cent probability of having a value between a minimum and maximum bound. The subspace (FMST) result is shown in Figs 11(c) and (d), while the Trans-D mean group velocity model and its corresponding raypath is shown in Figs 11(e) and (f). Immediately evident upon comparison of the FMST and Trans-D result is the failure of FMST to update the reference model in areas of low ray path coverage, particular on the eastern edge of the study area but also along parts of the northern and southern coasts, and western tip of Java, where the velocity of the final model is unchanged from that of the reference model, $2.25 \mathrm{~km} \mathrm{~s}^{-1}$. Furthermore, the velocity of the FMST model in Fig. 11(c) is almost everywhere lower than that of the Trans-D model, and in many places approaches the lower bound of the 95 per cent credibility interval of the Trans-D solution (Fig. 11a). This suggests that a combination of the damping and smoothing regularization (the 2 nd and 3 rd terms, respectively on the right-hand side of eq. 1), have caused FMST to not only retain the reference velocity along the edges of the model, but that this has 'bled' into the rest of the model, leading to velocities everywhere biased to low values. This is also evident from the negative skew of the traveltime residuals in Fig. 11(h).

We increased the reference velocity model to $2.75 \mathrm{~km} \mathrm{~s}^{-1}$, the value of Trans-D model along its eastern edge and re-ran FMST. 


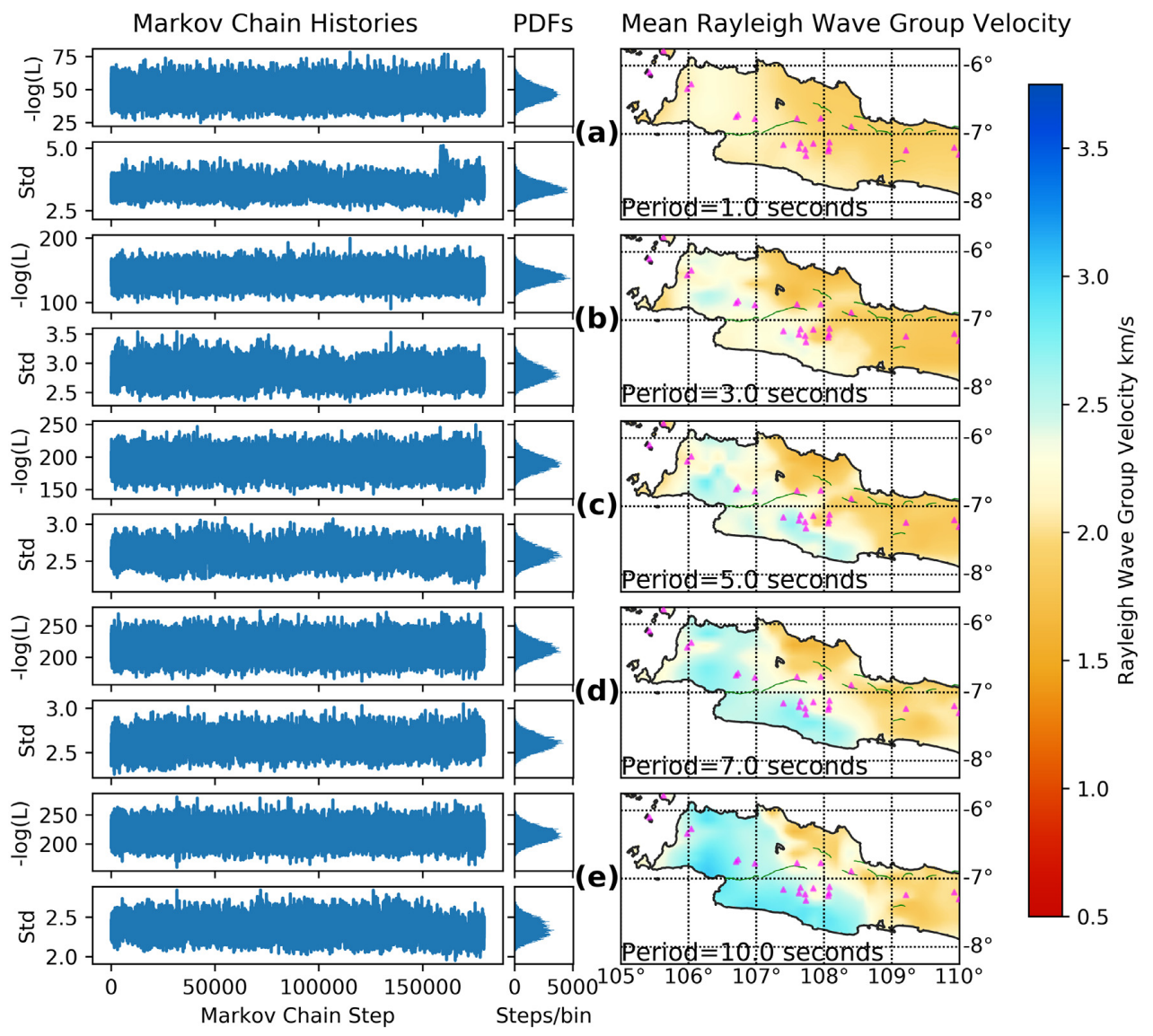

Figure 9. Tomography results for periods $1-25 \mathrm{~s}$ using non-linear Trans-D inversion. The left-hand side of each panel (a-j) image shows the Markov chain histories for the negative logarithm of the likelihood and the standard deviation of data errors $\sigma$. The 'flat' character of these histories strongly suggests a convergence of the Markov chains. The images on the right of panels (a-j) show maps of the Rayleigh wave group velocity calculated as the average of $a$ posteriori PDF sampled using RJMcMC. Red colour indicates low group velocity and blue colour indicates high group velocity. The green lines are active faults in West Java and the magenta triangles are locations of active volcanoes.

The resulting model is shown in Fig. 11(d), which is almost identical to the mean Trans-D model (Fig. 11e), and has a residual distribution centred on zero (Fig. 11i) and slightly narrower than the residual distribution in Fig. 11(h) (FMST reference velocity $2.25 \mathrm{~km} \mathrm{~s}^{-1}$ ) but slightly wider than the Trans-D residual distribution (Fig. 11g). We also note that the latter agrees well with a normal distribution having $\sigma=2.75$, the value estimated in the Trans-D inversion (Fig. $11 \mathrm{e})$. While in this case both the reference model and the $\sigma$ used in the FMST inversion could have been manually adjusted using visual inspection of only the FMST results and residual distribution, Trans-D finds appropriate values for these in a natural way that is driven by the data, since it uses no regularization (either to a reference model or for model smoothness) and the value of mean velocity or reference velocity is automatically adjusted in the inversion.

FMST's dependence on the reference model was not as easy to discern for all periods, however, Fig. 12 shows a comparison of Trans-D and FMST results similar to that in Fig. 11, but for a period of $3 \mathrm{~s}$. Here we see that again the FMST model obtained using a reference velocity of $2.25 \mathrm{~km} \mathrm{~s}^{-1}$ (Fig. 12c) has retained this value along some of the poorly sampled edges of the model [note ray path coverage in Fig. 12(g)]. In this case, the Trans-D result in Fig. 12 (e) also has about $2.25 \mathrm{~km} \mathrm{~s}^{-1}$ along some of the poorly sampled edges of the model, except for the eastern edge which has a velocity of about $1.75 \mathrm{~km} \mathrm{~s}^{-1}$. A subsequent FMST inversion with reference velocity $1.75 \mathrm{~km} \mathrm{~s}^{-1}$ produced the result in Fig. 12(d), which retained this reference velocity along all the poorly sampled edges of the model. Finally, we performed an FMST inversion using the TransD mean model of Fig. 12(e) as the reference model, resulting in the model of Fig. 12(f), which has velocity values in the unsampled edges that are similar to those of the Trans-D model, and results in smaller residuals than was the case for either inversion run with uniform reference velocity [Fig. 12k versus Figs 12(h)-(i)].

The different values for group velocity obtained along the unsampled edges of the study area in Fig. 12. and S7 are of course not particularly meaningful. However, all of the models in Figs 12(c)-(f) (and S7a-r) also exhibit differences in the well-sampled parts of the model not close to the edges, and these need to be understood. We surmise that, for the FMST results in Figs 12(c)-(e), the structure that gives rise to the differences between them in the well-sampled regions is spurious, in the sense that it is driven by changes in our choice for reference velocity model and regularization parameter values. While the velocity in the poorly sampled regions of the Trans-D model may not be meaningful, they are at least driven by fits to the data in the well-sampled parts of the model, and not vice versa. We also note that the Trans-D residuals are generally smaller than the FMST residuals and that the FMST residuals tend to get smaller when we incorporate information from the corresponding 


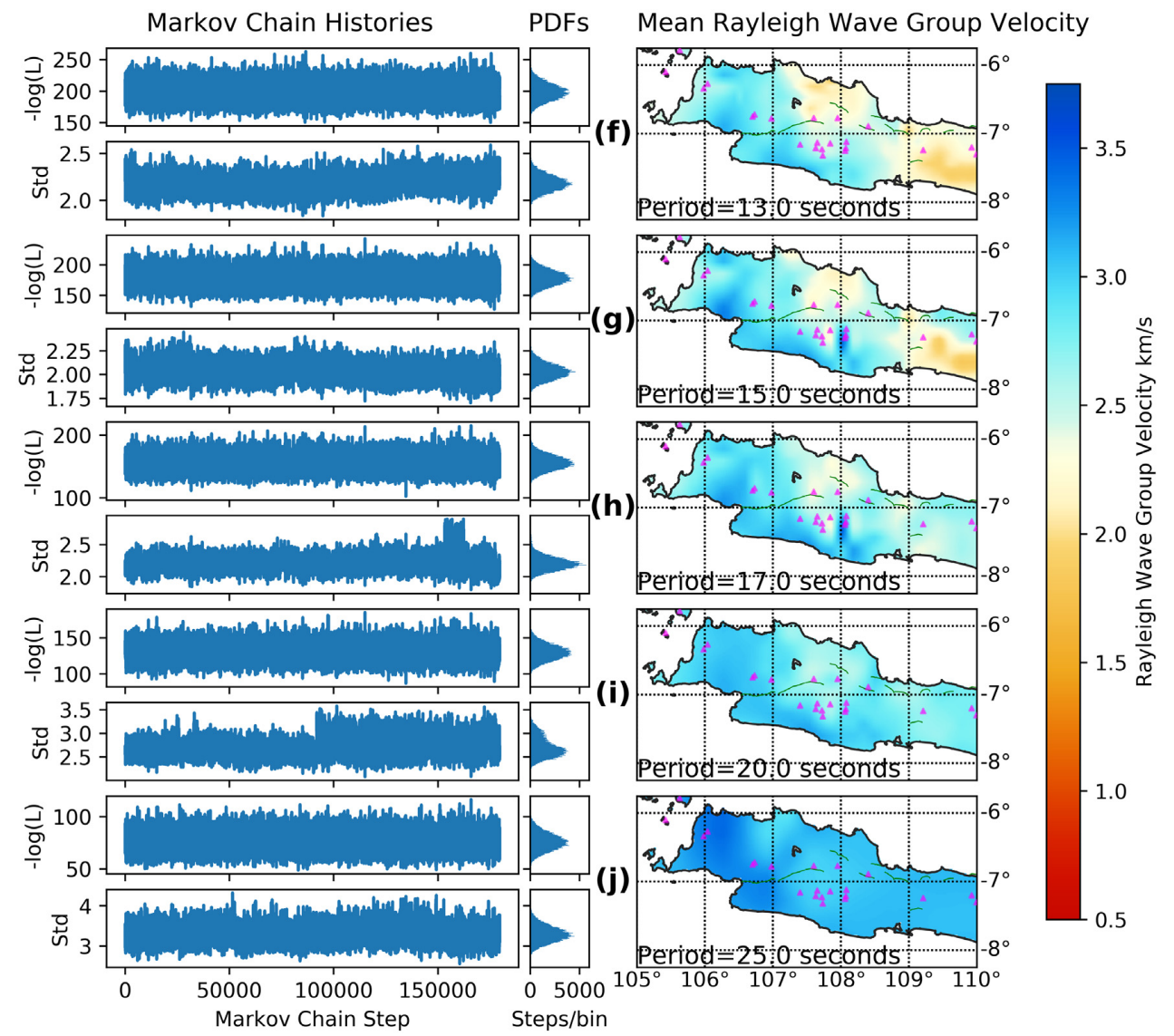

Figure 9. (Continued.)

Trans-D results [see e.g. Figs 11(g)-(i) and Figs 12(h)-(k)]. We conclude from this that the Trans-D method is achieving a more effective exploration of the model space, even though for FMST convergence always seemed to be reached after only a few iterations (see Fig. S3).

A simple and objective way to determine a suitable initial velocity for FMST is to use the average velocity estimated from the Trans-D inversion. We did this for each period and display the results in Fig. S7, which show similar behaviour to that described above. For the longest periods, 20-25 s (Fig. S7n-t), this new average velocity represents the study area reasonably well, and the slight departures of group velocity from this average value within the well-sampled part of the study area are similar for FMST and Trans-D Tree. For the remaining periods, however, the velocity is always lower in the east than in the west, with notable differences between the FMST and Trans-D Tree group velocities in the well-sampled part of the model domain. In this case Trans-D Tree always accommodates a more extensive spread of low velocity in the east than FMST, and we believe this is due to the same combination of damping and smoothing regularization in FMST as described above for the $3 \mathrm{~s}$ group velocity results.

\section{DISCUSSION OF THE GROUP VELOCITY RESULTS}

The results for Rayleigh wave group velocities maps for selected periods obtained by regularized subspace inversion, and by Trans-D Tree inversion are shown in Figs 7 and 9, 11, 12, respectively (the corresponding maps for all periods are shown in the Supplementary material, Figs S4 and S5, respectively). Both the subspace and the Trans-D Bayesian results have a similar overall pattern. For periods of 1-10 s, the northeastern half of western Java is characterized by a low group velocity, $2 \mathrm{~km} \mathrm{~s}^{-1}$ or less, while high velocities of $2.5 \mathrm{~km} \mathrm{~s}^{-1}$ or greater characterize the southwestern half [see Figs 9(c)-(e), for 5-10 s period]. This high group velocity in the southwest corresponds to an area of Eocene and Miocene sedimentary and volcanic deposits that include the Ciletuh, Jampang and Bayah Formations (some of the oldest rocks in western Java) as well as Pliocene sediments in westernmost Java (Clements et al. 2009; Clements \& Hall 2011). The low velocity in the northeast probably reflects deep intermontane basins near the centre of the study area and sedimentary basins and along the northern coastal plains resulting from depositional processes associated with products of late Tertiary and Quaternary volcanism (see Kartadinata et al. 2002; Nasution et al. 2004; Daryono et al. 2019).

For longer periods of 13-25 s, the group velocity gradually increases throughout western Java, which presumably reflects the transition to the crystalline basement and eventually the Moho. We also observed that some group velocity anomalies as low as $2.25 \mathrm{~km} \mathrm{~s}^{-1}$ persist to periods as long as $15-17 \mathrm{~s}$ [see Figs 9(g)-(h)], and these may be correlated with centres of volcanic activity. One large anomaly lies in the north of the central part of the study area, just north of Tangkuban Perahu, an active volcano that experienced a major eruption as recently as $40 \mathrm{ka}$, but which is a remnant of the much larger Sunda volcano, that collapsed in a huge caldera eruption lasting over 200-50 ka, whose eruptive products cover an area of about $200 \mathrm{~km}^{2}$ with thickness varying from 8 to $180 \mathrm{~m}$ (Nasution et al. 2004). Further south is a smaller anomaly centred on Guntur 

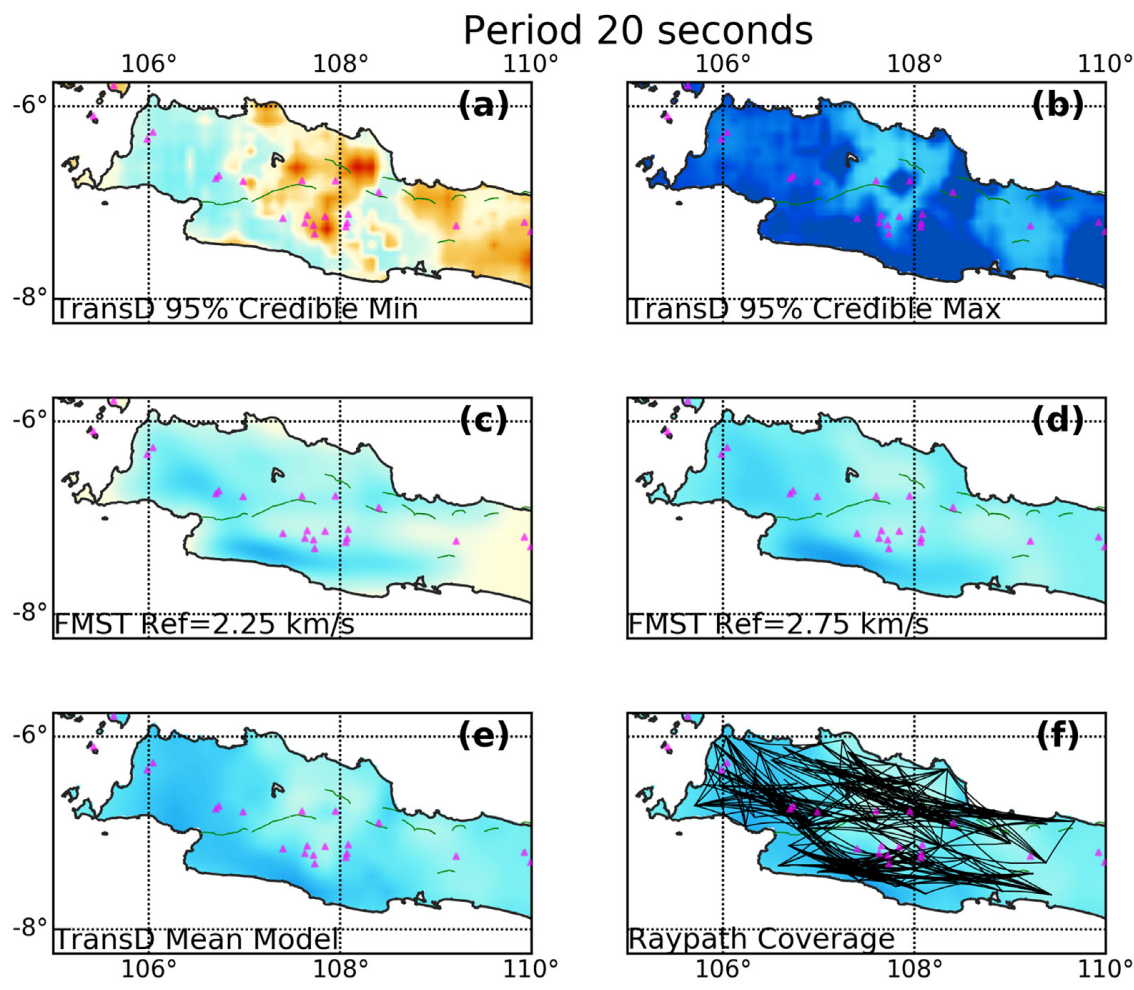

$-3.0$
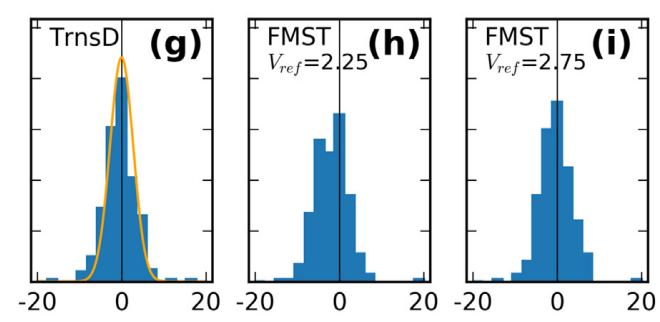

1.0

0.5

Figure 11. Comparison of tomography results for 20 s Rayleigh wave group velocity. (a,b) Minimum and maximum bounds, respectively, for the Trans-D 95 per cent credibility interval. (c,d) FMST results for reference velocities of 2.25 and $2.75 \mathrm{~km} \mathrm{~s}^{-1}$, respectively. (e) The Trans-D mean model. Panel (f) as (e) but with ray path coverage. Panels ( $\mathrm{g}-\mathrm{i}$ ) Residual histograms for the Trans-D, FMST with reference velocity $=2.25 \mathrm{~km} \mathrm{~s}^{-1}$, and FMST with reference velocity $=2.75 \mathrm{~km} \mathrm{~s}^{-1}$, respectively. The orange curve in $(\mathrm{g})$ is the normal PDF with $\sigma=2.75$ and normalized to that of the Trans-D residual histogram.

volcano, whose frequent eruptions in the 19th century make it one of the most active volcanoes in western Java.

\section{CONCLUDING REMARKS}

In this study, we applied the ANT method to image the Rayleigh wave group velocity structure in the western part of Java using 85 stations. We considered two approaches to the highly non-linear problem of surface wave group velocity inversion, one a traditional optimization approach that used iterative, linearized (subspace or FMST, see Rawlinson et al. 2006) inversion, and the other a probabilistic sampling (Trans-D Bayesian, see Hawkins \& Sambridge 2015) approach that allowed for data noise and model parametrization to adapt to fit the data as part of the inversion.

Our study found that, while computationally expensive, the Trans-D approach offered important advantages over FMST, including an apparently more extensive exploration of the model space as evidenced by a reduced residual misfit, and rigorous quantification of uncertainty. Also, Trans-D does not suffer from sensitivity to a reference model and regularization parameters, which our results suggest can introduce spurious structure into solutions obtained using FMST (and presumably similar optimization methods). While it might be possible for methods like FMST to avoid such sensitivity to regularization if the reference model and regularization parameter values are judiciously chosen, we found that this choice was not always obvious. Moreover, because Trans-D results can be aggregated over an extensive sampling of the parameter space (e.g. mean or median of the a postiori PDF), we believe it provides a more robust characterization of spatial variation in Rayleigh wave group velocity that better reflects the information content of the data than is the case for optimization methods like FMST.

Our inversion for Rayleigh wave group velocity structure in western Java shows that for short periods (1-10 s), spatial variations in group velocity closely follow the age of the sediments and volcanic deposits that comprise the surface geology of western Java. For longer periods (13-25 s), the group velocities increase to reflect the transition to the crystalline basement and the Moho, but some low group velocity anomalies for periods as long as $15-17$ s correlate well with centres of volcanic activity in western Java.

We hope that future work will see our ANT data set combined with ANT data sets covering central and eastern Java (Zulfakriza et al. 2014 and Martha et al. 2017, respectively). Also, we would 

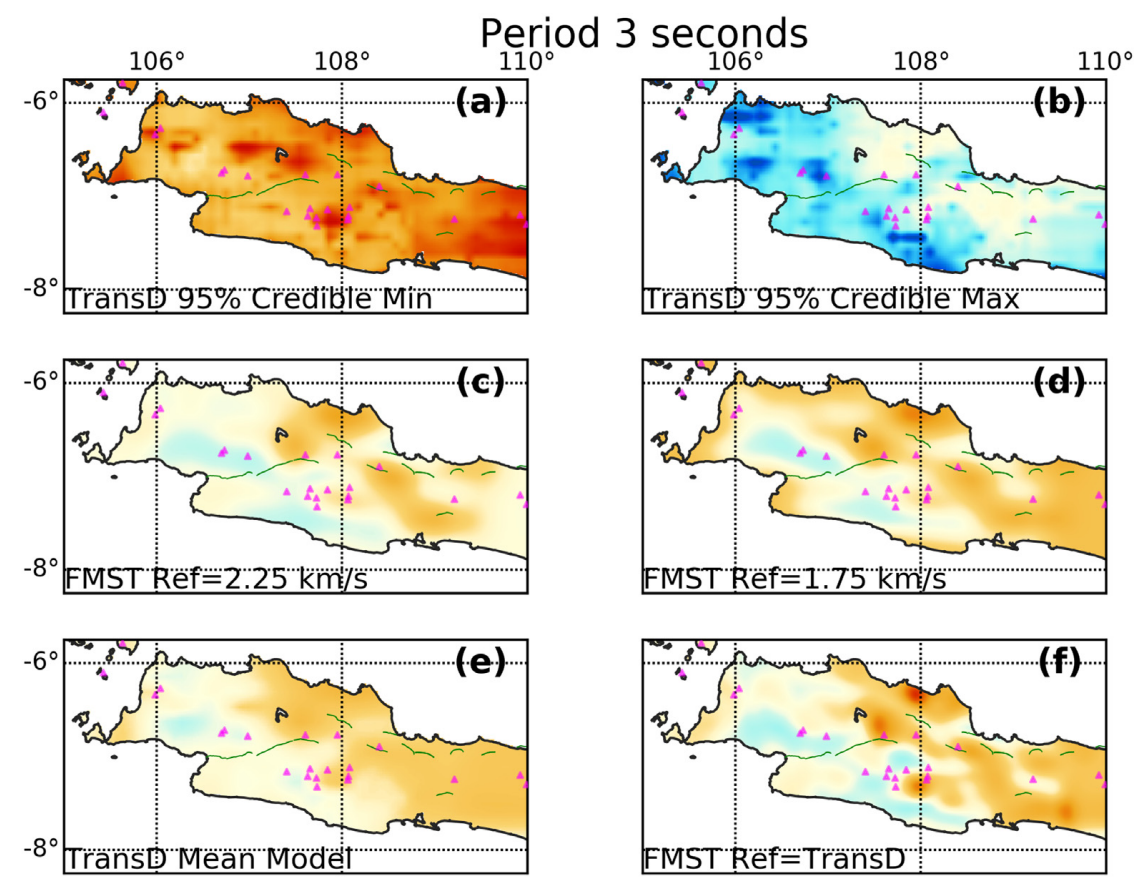

3.5

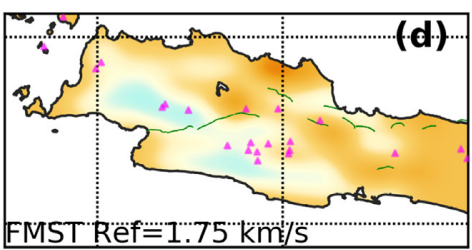

$-3.0$
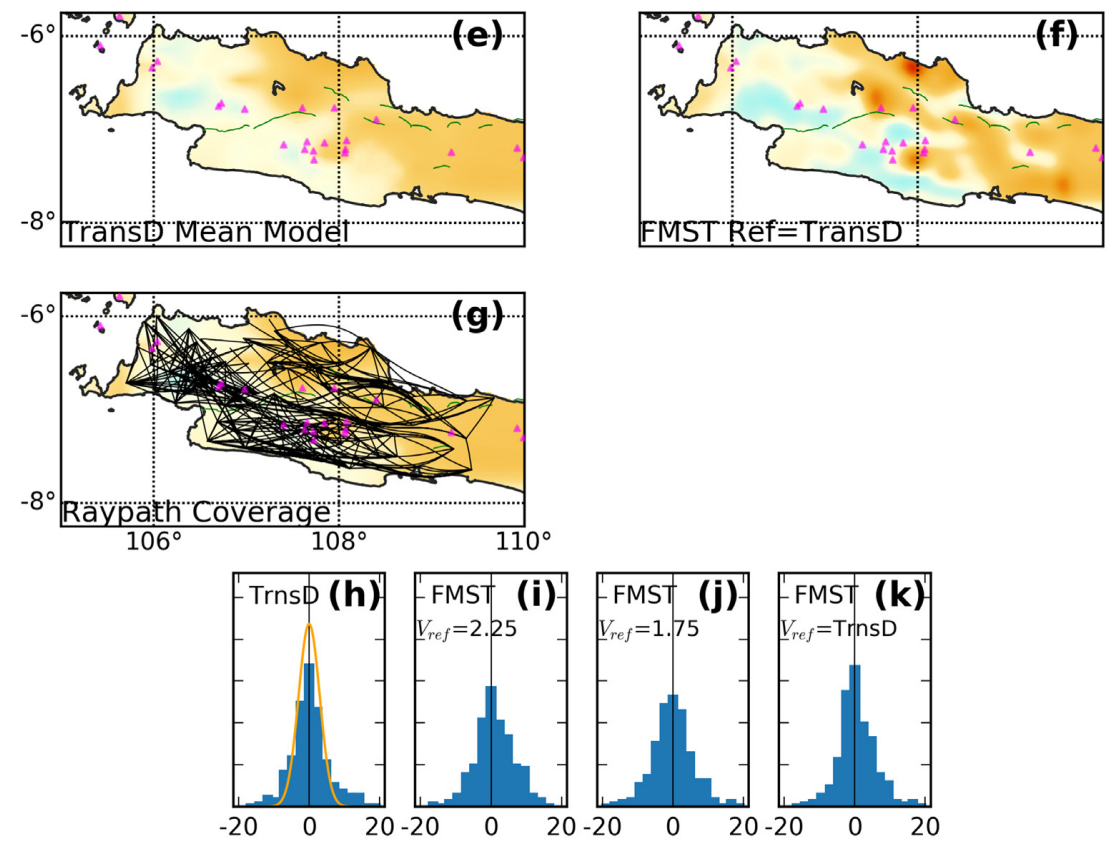

1.0

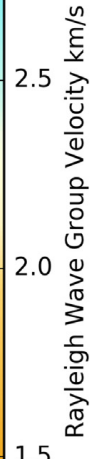

Figure 12. Comparison of tomography results for $3 \mathrm{~s}$ Rayleigh wave group velocity. (a,b) minimum and maximum bounds, respectively, for the Trans-D 95 per cent credibility interval. (c,d) FMST results for reference velocities of 2.25 and $1.75 \mathrm{~km} \mathrm{~s}^{-1}$, respectively. (e) The Trans-D mean model and (f) FMST result for reference velocities using the Trans-D model of (e). (g) as (f) but with ray path coverage. (h-k) Residual histograms of (c-f), respectively. The orange curve in (h) is the normal PDF with $\sigma=2.90$ and normalized to that of the Trans-D residual histogram.

like to use the Trans-D method in a multiscale approach that combines these large-scale data sets with much more densely spaced seismometer deployments targeted at basin structure and sources of volcanic activity (e.g. Saygin et al. 2016; Widiyantoro et al. 2018).

\section{ACKNOWLEDGEMENTS}

We are grateful to the Australian National University for allowing their instruments to be used in this study, and the Meteorology, Climatology and Geophysics Agency of Indonesia (BMKG) for the support in the acquisition process. We are also grateful to the PMDSU scholarship granted to S. Rosalia from the Ministry of Research, Technology, and Higher Education of the Republic of Indonesia (2015-2019). This work was partially funded by the Ministry of Public Works and Housing, and the Indonesian Ministry of Research, Technology and Higher Education under WCU Program 2019 managed by ITB awarded to S. Widiyantoro. We thank
Nick Rawlinson and Huajian Yao for their codes. We also thank the anonymous reviewers who helped to improve the quality of this paper. Figs 1(b), 2(a), S2 and S4 were prepared using the GMT Software (Wessel \& Smith 1998). Figs 5-7, 9-12, S4, and S5 were prepared using the matplotlib package from Python (Hunter 2007). This research was undertaken with the assistance of resources from the National Computational Infrastructure, which is supported by the Australian Government.

\section{REFERENCES}

Agostinetti, N.P. \& Malinverno, A., 2010. Receiver function inversion by trans-dimensional Monte Carlo sampling, Geophys. J. Int., 181(2), 858872.

Bensen, G.D., Ritzwoller, M.H., Barmin, M.P., Levshin, A.L., Lin, F., Moschetti, M.P., Shapiro, N.M. \& Yang, Y., 2007. Processing seismic ambient noise data to obtain reliable broad-band surface wave 
dispersion measurements, Geophys. J. Int., 169, doi:10.1111/j.1365246X.2007.03374.x.

Bird, P., 2003. An updated digital model of plate boundaries, Geochem., Geophys. Geosyst., 4, doi:10.1029/2001GC000252.

Bodin, T. \& Sambridge, M., 2009. Seismic tomography with the reversible jump algorithm, Geophys. J. Int., 178(3), 1411-1436.

Bodin, T., Sambridge, M., Tkalčić, H., Arroucau, P., Gallagher, K. \& Rawlinson, N., 2012. Transdimensional inversion of receiver functions and surface wave dispersion, J. geophys. Res., 117(B2), B02301, doi:10.1029/2011JB008560.

Claerbout, J.F., 1968. Synthesis of a layered medium from its acoustic transmission response, Geophysics, 33, 264-269.

Clements, B. \& Hall, R., 2011. A record of continental collision and regional sediment flux for the Cretaceous and Palaeogene core of SE Asia: implications for early Cenozoic palaeogeography, J. Geol. Soc. Lond., 168, $1187-1200$

Clements, B., Hall, R., Smyth, H.R. \& Cottam, M.A., 2009. Thrusting of a volcanic arc: a new structural model for Java, Petrol. Geosci., 15, 159174

Cohen, A., Daubechies, I. \& Feauveau, J.C., 1992. Biorthogonal bases of compactly supported wavelets, Commun. Pure appl. Math., 45, 485-560, Wiley Online Library.

Daryono, M.R., Natawidjaja, D.H., Sapiie, B. \& Cummins, P., 2019 Earthquake geology of the Lembang fault, West Java, Indonesia, Tectonophysics, 751, 180-191.

DEMOGRAPHIA, 2018. Demographia World Urban Areas 14th Annual Edition: 201804, 22.

Dettmer, J., Molnar, S., Steininger, G., Dosso, S.E. \& Cassidy, J.F., 2012. Trans-dimensional inversion of microtremor array dispersion data with hierarchical autoregressive error models, Geophys. J. Int., 188, 719-734.

Dettmer, J., Hawkins, R., Cummins, P.R., Hossen, J., Sambridge, M., Hino, R. \& Inazu, D., 2016. Tsunami source uncertainty estimation: the 2011 Japan tsunami, J. geophys. Res., 121, 4483-4505.

Dziewonski, A.M., Bloch, S. \& Landisman, M., 1969. A technique for the analysis of transientseismic signals, Bull. seism. Soc. Am., 59, 427-444.

Gao, H., Humphreys, E.D., Yao, H. \& van der Hilst, R.D., 2011. Crust and lithosphere structure of the northwestern U.S. with ambient noise tomography: terrane accretion and Cascade arc development, Earth planet. Sci. Lett., 304, 202-211.

Green, P.J., 1995. Reversible jump Markov Chain Monte Carlo computation and Bayesian model determination, Biometrika, 82, 711-732.

Griffin, J., Nguyen, N., Cummins, P. \& Cipta, A., 2018. Historical earthquakes of the eastern Sunda arc: source mechanisms and intensity-based testing of Indonesia's National Seismic Hazard Assessment, Bull. seism. Soc. Am., 109(1), 43-65.

Hable, S., Sigloch, K., Barruol, G., Stähler, S.C. \& Hadziioannou, C., 2018. Clock errors in land and ocean bottom seismograms: high-accuracy estimates from multiple-component noise cross-correlations, Geophys. J. Int., 214, 2014-2034

Hamilton, W.B., 1979. Tectonics of the Indonesian Region, US Govt. Print. Off, doi:10.3133/pp1078

Hawkins, R. \& Sambridge, M., 2015. Geophysical imaging using transdimensional trees, Geophys. J. Int., 203, 972-1000.

Hawkins, R., Brodie, R. \& Sambridge, M. 2018. Bayesian trans-dimensional inversion of airborne electromagnetic 2D conductivity profiles, Explor Geophys., 49(2), 134-147.

Hejrani, B., Tkalčić, H. \& Fichtner, A. 2017. Centroid moment tensor catalogue using a 3-D continental scale Earth model: application to earthquakes in Papua New Guinea and the Solomon Islands, J. geophys. Res., 122(7), 5517-5543.

Hunter, J.D., 2007. Matplotlib: A 2D graphics environment, Comp. Sci. Eng., 9(3), 90-95.

Kartadinata, M.N., Okuno, M., Nakamura, T. \& Kobayashi, T., 2002. Eruptive history of Tangkuban Perahu Volcano, West Java, Indonesia, J. Geogr. (Chigaku Zasshi), 111, 404-409.

Kennett, B.L.N., Sambridge, M.S. \& Williamson, P.R., 1988. Subspace methods for large inverse problems with multiple parameter classes, Geophys. J., 94, 237-247.
Larose, E. et al., 2006. Correlation of random wavefields: an interdisciplinary review, Geophysics, 71(4), SI11-SI21.

Lin, F.C., Ritzwoller, M.H., Townend, J., Bannister, S. \& Savage, M.K., 2007. Ambient noise Rayleigh wave tomography of New Zealand, Geophys. J. Int., 170, doi:10.1111/j.1365-246X.2007.03414.x.

Lobkis, O.I. \& Weaver, R.L., 2001. On the emergence of the Green's function in the correlations of a diffuse field, J. acoust. Soc. Am., 110, 3011-3017, ASA.

Malinverno, A., 2002. Parsimonious Bayesian Markov chain Monte Carlo inversion in a nonlinear geophysical problem, Geophys. J. Int., 151, 675688.

Malod, J.A., Karta, K., Beslier, O.M. \& Zen, M.T., Jr., 1995. From normal to oblique subduction: tectonic relationships between Java and Sumatra, J. SE Asian Earth Sci., 12, 85-93.

Martha, A.A., Cummins, P., Saygin, E. \& Widiyantoro, S., Masturyono., 2017. Imaging of upper crustal structure beneath East Java-Bali, Indonesia with ambient noise tomography, Geosci. Lett., 4, doi:10.1186/s40562017-0080-9.

Minsley, B.J., 2011. A trans-dimensional Bayesian Markov chain Monte Carlo algorithm for model assessment using frequency-domain electromagnetic data, Geophys. J. Int., 187, 252-272.

Nasution, A., Kartadinata, M.N., Kobayashi, T., Siregar, D., Sutaningsih, E., Hadisantono, R. \& Kadarstia, E., 2004. Geology, age dating and geochemistry of the Tangkuban Parahu geothermal area, West Java, Indonesia, $J$. Geotherm. Res. Soc. Jpn., 26, 285-303.

Nugraha, A.D. et al., 2018. Hypocenter relocation along the Sunda Arc in Indonesia, using a 3D seismic-velocity model, Seismol. Res. Lett., 89, 603-612.

Pilia, S., Rawlinson, N., Direen, N.G., Reading, A.M., Cayley, R., Pryer, L., Arroucau, P. \& Duffett, M. 2015. Linking mainland Australia and Tasmania using ambient seismic noise tomography: implications for the tectonic evolution of the east Gondwana margin, Gondwana Res., 28, 1212-1227.

Porritt, R.W., Miller, M.S., O’Driscoll, L.J., Harris, C.W., Roosmawati, N. \& Teofilo da Costa, L., 2016. Continent-arc collision in the Banda Arc imaged by ambient noise tomography, Earth planet. Sci. Lett., 449, 246258

Pranata, B., Yudistira, T., Saygin, E., Cummins, P.R., Widiyantoro, S.,Zulfakriza \& Nugraha, A.D., 2016. Bandung seismic experiment: towards tomographic imaging by using ambient seismic noise, AIP Conf. Proc., 1730, doi:10.1063/1.4947382.

Rawlinson, N. \& Sambridge, M., 2005. The fast marching method: an effective tool for tomographic imaging and tracking multiple phases in complex layered media, Explor. Geophys., 36, 341-350.

Rawlinson, N., Reading, A.M. \& Kennett, B.L.N., 2006. Lithospheric structure of Tasmania from a novel form of teleseismic tomography, J. geophys. Res., 111, doi:10.1029/2005JB003803.

Ridwan, M., Cummins, P., Widiyantoro, S. \& Irsyam, M., 2019. Site characterization using microtremor array and seismic hazard assessment for Jakarta, Indonesia, Bull. seism. Soc. Am., doi:10.1785/0120190040.

Rosalia, S., Widiyantoro, S., Yudistira, T., Cummins, P. \& Nugraha, A.D., 2019. Western Java ambient noise tomography: a preliminary result, $J$. Phys. Conf. Ser., 1204, 12099.

Sambridge, M., 2014. A parallel tempering algorithm for probabilistic sampling and multimodal optimization, Geophys. J. Int., 192, 357-374.

Sambridge, M., Gallagher, K., Jackson, A. \& Rickwood, P., 2006. Transdimensional inverse problems, model comparison and the evidence, Geophys. J. Int., 167, 528-542.

Saygin, E. \& Kennett, B.L.N., 2012. Crustal structure of Australia from ambient seismic noise tomography, J. geophys. Res., 117, doi:10.1029/2011JB008403.

Saygin, E. et al., 2016. Imaging architecture of the Jakarta Basin, Indonesia with transdimensional inversion of seismic noise, Geophys. J. Int., 204, 918-931.

Sethian, J.A., 1999. Fast marching methods, SIAM Rev., 41, 199-235.

Shapiro, N.M. \& Campillo, M., 2004. Emergence of broadband Rayleigh waves from correlations of the ambient seismic noise, Geophys. Res. Lett., 31, doi:10.1029/2004GL019491. 
Snieder, R., 2007. Extracting the Green's function of attenuating heterogenous acoustic media from uncorrelated waves, J. acoust. Soc. Am., 121(5), $2637-2643$.

Snieder, R. \& Larose, E., 2013. Extracting earth's elastic wave response from noise measurements, Ann. Rev. Earth planet. Sci., 41, 183-206.

van Bemmelen, R.W., 1949. The Geology of Indonesia 1, A. General Geology of Indonesia and Adjacent Archipelagoes, US Government Printing Office.

Wapenaar, K., 2003. Synthesis of an inhomogeneous medium from its acoustic transmission response, Geophysics, 68(5), 1756-1759.

Wapeenar, K., Fokkema, J. \& Snieder, R., 2005. Retrieving the Green's function in an open system by cross correlation: a comparison of approaches (L), J. acoust. Soc. Am., 118(5), 2783-2786.

Wessel, P. \& Smith, W.H.F., 1998. New, improved version of generic mapping tools released, EOS, Trans. Am. Geophys. Un., 79, 579-579.

Widiyantoro, S. \& van der Hilst, R.D., 1996. Structure and evolution of lithospheric slab beneath the Sunda Arc, Indonesia, Science, 271, 15661570 .

Widiyantoro, S. et al., 2018. Seismic imaging and petrology explain highly explosive eruptions of Merapi volcano, Indonesia, Sci. Rep., 8, doi:10.1038/s41598-018-31293-w.

Yao, H., van der Hilst, R.D. \& de Hoop, M.V., 2006. Surface-wave array tomography in SE Tibet from ambient seismic noise and two-station analysis: I. Phase velocity maps, Geophys. J. Int., 166, 732-744.
Yao, H., Gouedard, P., Collins, J.A., McGuire, J.J. \& van der Hilst, R.D., 2011. Structure of young East Pacific Rise lithosphere from ambient noise correlation analysis of fundamental-and higher-mode Scholte-Rayleigh waves, C.R. Geosci., 343(8-9), 571-583.

Young, M.K., Rawlinson, N., Arroucau, P., Reading, A.M. \& Tkalčič, H., 2011. High-frequency ambient noise tomography of southeast Australia: new constraints on Tasmania's tectonic past, Geophys. Res. Lett., 38, doi:10.1029/2011GL047971.

Yudistira, T. \& Widiyantoro, S., 2016. Characteristics of seismic noise in Central Java, Indonesia, AIP Conf. Proc., 1730, doi:10.1063/1.4947381.

Zulfakriza, Z., Saygin, E., Cummins, P.R., Widiyantoro, S., Nugraha, A.D., Lühr, B.-G. \& Bodin, T., 2014. Upper crustal structure of central Java, Indonesia, from transdimensional seismic ambient noise tomography, Geophys. J. Int., 197, 630-635.

\section{SUPPORTING INFORMATION}

Supplementary data are available at $G J I$ online.

Supplementary_Rosalia et al_acc.docx

Please note: Oxford University Press is not responsible for the content or functionality of any supporting materials supplied by the authors. Any queries (other than missing material) should be directed to the corresponding author for the paper. 